Please do not remove this page

RMIT

UNIVERSITY

\title{
Review of methodologies for composite material modelling incorporating failure
}

Orifici, Adrian; Herszberg, l; Thomson, Rodney

https://researchrepository.rmit.edu.au/esploro/outputs/9921861331501341/filesAndLinks?institution=61RMIT_INST\&index=null

Orifici, A., Herszberg, I., \& Thomson, R. (2008). Review of methodologies for composite material modelling incorporating failure. Composite Structures, 86(1-3), 194-210.

https://doi.org/10.1016/j.compstruct.2008.03.007

Document Version: Accepted Manuscript

Published Version: https://doi.org/10.1016/j.compstruct.2008.03.007

Repository homepage: https://researchrepository.rmit.edu.au

(c) 2008 Elsevier Ltd. All rights reserved.

Downloaded On 2023/04/26 20:46:02 +1000

Please do not remove this page 
Thank you for downloading this document from the RMIT Research Repository.

The RMIT Research Repository is an open access database showcasing the research outputs of RMIT University researchers.

RMIT Research Repository: http://researchbank.rmit.edu.au/

\section{Citation:}

Orifici, A, Herszberg, I and Thomson, R 2008, 'Review of methodologies for composite material modelling incorporating failure', Composite Structures, vol. 86, no. 1-3, pp. 194-210.

See this record in the RMIT Research Repository at:

https://researchbank.rmit.edu.au/view/rmit:4602

Version: Accepted Manuscript

Copyright Statement: (C) 2008 Elsevier Ltd. All rights reserved.Creative Commons Attribution-NonCommercial-NoDerivatives 4.0 International License

Link to Published Version:

http://dx.doi.org/10.1016/j.compstruct.2008.03.007 


\title{
Review of methodologies for composite material modelling incorporating failure
}

\author{
A.C. Orifici ${ }^{\text {a b, }}{ }^{*}$, I. Herszberg ${ }^{\text {b }}$, R.S. Thomson ${ }^{\text {b }}$ \\ ${ }^{a}$ School of Aerospace, Mechanical and Manufacturing Engineering, Royal Melbourne Institute of Technology, GPO Box 2476V, \\ Melbourne, Victoria, 3001, Australia \\ ${ }^{\mathrm{b}}$ Cooperative Research Centre for Advanced Composite Structures, 506 Lorimer Street, Fishermans Bend, Victoria, 3207, Australia
}

\begin{abstract}
Advanced composite materials are finding increasing application in aerospace, marine and many other industries due to the advantages in performance, structural efficiency and cost they provide. However, despite years of extensive research around the world, a complete and validated methodology for predicting the behaviour of composite structures including the effects of damage has not yet been fully achieved. The Cooperative Research Centre for Advanced Composite Structures (CRC-ACS) is leading a currently running collaborative project to develop a methodology for determining mechanical behaviour and failure in composite structures. Key drivers of the project are the use of multi-axial testing machines for material characterisation and an appreciation of the issues involved due to the different length scales of any analysis. As part of the project, a critical review was performed to assess the state of the art in material constitutive modelling and composite failure theories. This paper summarises the results of the review, which includes a discussion of the various theories and approaches within the context of the dissipated energy density framework. The results of the review will be applied within the project to select appropriate constitutive modelling and failure approaches for implementation within a data-driven material characterisation methodology.
\end{abstract}

Keywords: Material characterisation; Constitutive modelling; Failure theories; Damage; Dissipated Energy Density

\section{Introduction}

Fibre-reinforced polymer (FRP) composites are finding increasing application in aerospace, marine and many other industries due to the advantages they provide in performance, structural efficiency and cost. However, despite years of extensive research around the world, a complete and validated methodology for predicting the behaviour of composite structures including the effects of damage has not yet been fully achieved. This is largely due to their complex nature, so that for any composite structure the performance and the development of damage leading to failure are dependent on a range of parameters including the geometry, material, lay-up, loading conditions, load history and failure modes.

An approach has been developed at the US Naval Research Laboratory (NRL) to characterise straininduced material damage that is based on the energy dissipated by a material undergoing irreversible damage processes [1]. This dissipated energy can be determined experimentally from the nonlinear behaviour of a

\footnotetext{
* Corresponding author. Fax +61 396764999.

E-mail address: a.orifici@crc-acs.com.au (A.C. Orifici).
}

specimen under loading, as shown in Figure 1. A dissipated energy density (DED) function, with units of energy per unit volume, can be determined from experimental testing and is postulated to be a property of the material. The DED function relates the strain at any point in the material to the dissipated energy, and as such measures the cumulative nonlinear softening effect all damage mechanisms, without requiring explicit knowledge of these mechanisms. The DED function has been used as a measure of local material softening due to load-induced damage, to quantify the nonlinear damage or global softening of composite materials and structures, or in a reciprocal sense to characterise material health.

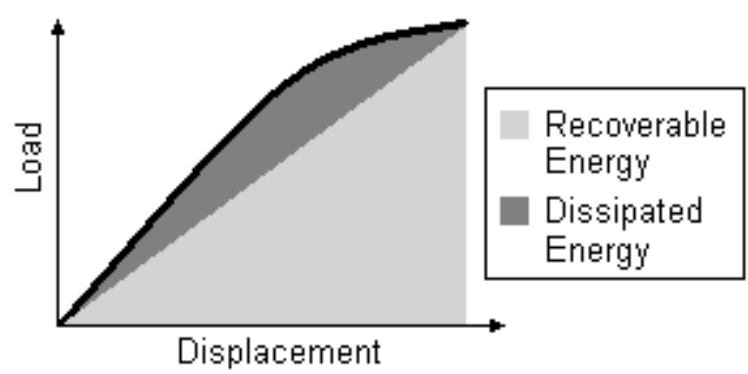

Figure 1: Dissipated energy as determined from material load-displacement behaviour. 
The DED function is determined in a data-driven approach that uses an extensive set of test data. This data is obtained from a multi-axial test machine, which is capable of inputting loading displacements in a number of degrees of freedom (DOF) simultaneously. The experimental procedure is used to determine a set of dissipated energy values at a range of data points throughout the displacement loading space. A linear polynomial form of the DED function is proposed as a function of strain and material coefficients. The strain coefficients are interpolation functions between points in the strain space, and the material coefficients are solved for using the experimental energy data. The DED function characterised in this way is specific to the ply material, lay-up and ply thickness, and needs to be repeated when changes to the laminate are made. For this reason, the data-driven approach is suited to a highly automated process, where for example a 3DOF machine developed at NRL can feed specimens in continuously and is capable of characterising up to 12 different laminates an hour [1]. Two generations of 6DOF machines have also been developed, and are capable of performing automated characterisation testing using the complete displacement loading space [2-3].

The DED function can then be incorporated into a nonlinear definition of the material constitutive behaviour, by assuming that the work potential is the sum of recoverable and dissipated parts. From this, a coupled system of nonlinear equations is defined that describes the stress-strain, equilibrium and straindisplacement relationships. The DED function is used to define a failure surface, and determine whether the material is in an inelastic or elastic domain. The stress state of the material is then determined in an iterative process, which requires the material coefficients of the DED function and material strain state to be initially estimated and then updated iteratively.

The Cooperative Research Centre for Advanced Composite Structures (CRC-ACS) is leading a four-year collaborative research project that aims to extend the data-driven approach developed at NRL and develop a characterisation methodology for composite materials to determine mechanical behaviour leading up to and including failure. The project involves validation of the approach using a range of different coupons and subcomponents as well as implementation into a suitable software package, with a focus on mitigating issues associated with analysis at difference length scales.
This paper summarises the results of a critical review performed within the project to assess the state of the art in material constitutive modelling and composite failure theories. The theories and approaches are then discussed within the context of the DED framework. The results of the review will be applied within the project to select appropriate constitutive modelling and failure approaches for implementation within a data-driven material characterisation methodology.

\section{Constitutive Modelling}

The constitutive model of a material system is the relation that is used to characterise its physical properties, and is necessary to describe the behaviour of the system under loading. Constitutive models can be classified as either explicit, implicit or hybrid, based on their form and their relationship to physically derived models of behaviour [3].

\subsection{Explicit}

Explicit constitutive models are the classical approach to defining the constitutive relationship of a material system, and connect the real properties of the system to its behaviour using physically-based theories. The mechanical behaviour of solids is normally defined as a constitutive stress-strain relation, where the stress is a function of the strain, strain rate, strain history, temperature and material properties. This can be done at the macroscopic or microscopic level.

The macroscopic level involves analysis at a range of scales that includes individual plies and laminates, as well as structural components and assemblies. Whilst each of these scales can be classified separately, they are all based on a constitutive model that uses smeared or averaged properties for the composite ply. The generalised stress-strain relationship is derived from the work potential of the system. At a macroscopic level, this equation is used to define the stiffness of a single ply, or of a complete laminate using Classical Laminate Plate Theory [4]. The determination of the stress and strain fields for the material is achieved by solving this equation with the strain-displacement, compatibility and equilibrium equations, and is commonly performed using finite element (FE) analysis.

At the microscopic level, the constitutive relationship is used to describe the relationship between the properties of the unit composite ply to its fibre and matrix 
constituents. More complex models may also include the interface and interphase region between the constituents [5], as well as the presence of voids or other imperfections. A generalised stress-strain law is defined in a similar manner, though typically also incorporates deformation due to thermal expansion, and is solved using mechanics of materials, theory of elasticity or an FE approach.

\subsection{Implicit}

Implicit constitutive models characterise the behaviour of a material using only a mathematical relationship between the inputs and outputs of a system and do not attempt to represent any of the underlying physics. Implicit models are more suited to represent highly complex and nonlinear material behaviour, where explicit models based on simple phenomenological investigations may not be able to capture all the relevant behaviour. In order to define an implicit model, the system being investigated is first expressed mathematically in terms of its inputs and outputs, and then a system identification process is used to find an optimum approximation function. This process requires a set of input-output data, such that the fitness of the approximation is dependent on the reliability of this data. For complex systems, the use of neural networks as a universal function approximator allows for accurate descriptions of material behaviour with multiple input and output variables [7]. Implicit constitutive models can be developed for any material, and have been demonstrated for a range of materials, including soil [8], piezoelectric [9] and FRP [10-11]. It is important to note that these models can only be used to predict behaviour within the range for which they were developed, which has implications for the application across different length scales.

\subsection{Hybrid}

Hybrid models combine features of explicit and implicit relations, and use both physically-based and approximation methods in order to characterise material behaviour. This type of model can be advantageous in balancing a consideration of the underlying theories or frameworks with the relative freedom of an approximation-based characterisation. An example hybrid relation is the DED approach described previously, where an arbitrary polynomial function is used to mathematically define the DED, which is a material property used to measure any energy lost due to nonlinearities. The DED is defined as a polynomial equation that is incorporated into the material constitutive relation, and solved using an iterative solution process. The hybrid model for DED has also been used in conjunction with a degradation model to simulate loss of stiffness due to material failure [12], and to characterise material damage in both an analysis and health monitoring context [3].

\section{Composite Failure}

\subsection{Failure Mechanisms}

Composite materials display a wide variety of failure mechanisms as a result of their complex structure and manufacturing processes, which include fibre failure, matrix cracking, buckling and delamination. Based on these failure mechanisms it can be more appropriate to consider the composite as a structure rather than as a material.

- Fibre failure is one of the simplest failure mechanisms to identify and quantify, and occurs when the loads applied to a composite structure cause fracture in the fibres.

- Matrix cracks are an intralaminar form of damage, and involve cracks or voids between fibres within a single composite layer, or lamina.

- Buckling is a structural phenomenon that occurs in compression or shear, and though not necessarily resulting in failure, the large deformations, bending and loss of structural capacity involved typically promotes other types of damage and leads to structural collapse.

- Delaminations are separations between internal layers of a composite laminate caused by high through-thickness stresses, and cause significant structural damage, particularly in compression.

\subsection{Damage Characterisation}

In the analysis of composite structures, various approaches are used to characterise the onset and progression of damage. This typically involves monitoring a particular type of parameter to predict and monitor damage development and growth. Though there are a variety of damage characterisation approaches, these can be generally categorised as being based on theories of strength or fracture mechanics. 
The strength, as defined by the allowable stresses for a material, can be used to characterise the initiation and growth of all types of damage. The application of the strength approach is usually fairly simple, with one or more strength criteria defined, and the material deemed to have been irreversibly damaged once these criteria are satisfied. The criteria themselves can range from single stress parameter limits, combinations of various stress terms, or normalisation of stress terms using structural or material values. Also, strength criteria can be applied so that each damage mechanism has a distinct criterion, or a more general damage criterion can be applied. There are also a number of parameters similar to stress that have been used to characterise damage including strain, force, displacement or rotation amongst others. It is important to note that strength-based characterisation of damage is most commonly applied to define the damage initiation, and not the progression of an existing damage region, and this is especially relevant for delaminations.

On the other hand, classical fracture mechanics is a theory that studies the growth of existing defects, and whilst not often used for most forms of composite damage, has been successfully applied to the study of delamination and debonding. Classical fracture mechanics were developed and applied for damage analysis of metals, in which a single crack propagates at a mostly uniform rate through the material. In fracture mechanics theory, the growth of a macroscopic defect is controlled by the rate of strain energy released in propagation, as compared to a threshold maximum strain energy release rate for that material, which as such is a measure of material toughness. The strain energy released in crack propagation is typically split into the separate mechanisms of crack growth: peeling, shearing and tearing, as seen in Figure 2.
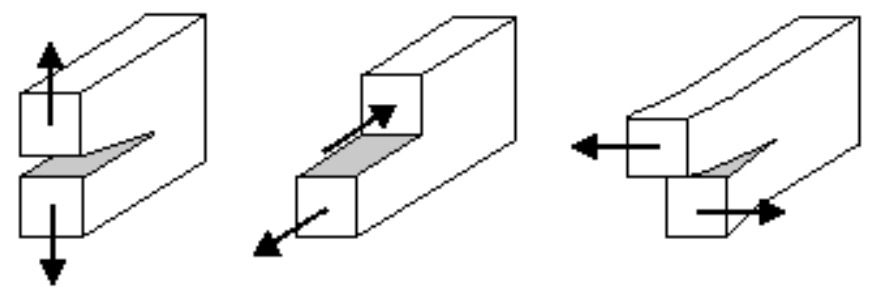

Figure 2: Crack growth modes a) I. Peeling b) II. Shearing c) III. Tearing.

The study of a single macroscopic crack in metals is analogous to the propagation of delamination, so that composite researchers almost without exception have applied classical fracture mechanics principles in order to study the growth of a pre-existing delamination. Numerous researchers investigating the behaviour of delamination failure have found that the strain energy release rate is affected by a wide range of factors, including loading, crack growth direction, proportion of the different crack opening modes, and orientation of plies bounding the delamination. Again, it is important to note that the classical fracture mechanics approach assumes a pre-existing crack, and generally does not characterise the initiation of damage.

A variety of methods have been developed to determine the strain energy release rate components from the results of FE analysis. Most methods make some assumptions regarding the crack front geometry and crack growth behaviour. Some examples include the Jintegral, equivalent domain integral, finite extension and virtual crack extension methods, and a comprehensive review of different approaches is given in [13]. One of the most popular approaches is the Virtual Crack Closure Technique (VCCT) [14], which unlike some of the other approaches is based on simple equations and can be performed in a single FE analysis. Another common approach is the Crack Tip Element method developed by Davidson [15], which has been shown to offer some improvements over the VCCT approach, particularly in analysing a crack between dissimilar plies.

\subsection{Material Characterisation}

All failure criteria are dependent on an experimental determination of material limits. There are a number of standards organisations, for example the International Standards Organisations (ISO), American Society for Testing and Materials (ASTM), or European Structural Integrity Society (ESIS), specifying testing procedures for a large range of material properties, though these are generally limited to strength and fracture mechanics parameters. Strength and other mechanical properties are determined with simple, well-established test procedures, such as compression, tensile, shear and three-point bend tests. Fracture mechanics tests are classified according to the mode, or combination of modes, of the loading applied to the specimen, which determines the properties able to be identified. These tests however can be relatively problematic for a number of reasons, and not all fracture mechanics properties are currently able to be determined reliably.

A feature of most current experimental characterisation techniques is their reliance on uniaxial testing machines, 
and their capability to identify only one or two material parameters per test coupon. Multiaxial testing machines have been developed to overcome these issues, and allow for the application of loads in a variety of degrees of freedom. The application of multiaxial testing machies for material characterisation requires an approach to determine a set of parameters from the multiaxial response of the specimen, such as the method developed for a 3DOF loading machine by Mast et al. [1]. Material identification in this manner can be specific for each material lay-up, type, architecture or specimen geometry investigated. However, approaches such as design of experiments [16] and online load path planning [17] have shown that the multiaxial testing approach can be optimised and made general enough for characterisation in a range of different scenarios.

\subsection{Failure Criteria}

The development of failure criteria for composite materials has been actively pursued for over 30 years by researchers around the world, and there are countless theories available in the literature. These criteria can be classified in a number of ways, including whether they are based on strength or fracture mechanics theories, whether they predict failure in a general sense or are specific to a particular failure mode, and whether they focus on in-plane or interlaminar failure. In this review, failure theories for in-plane and interlaminar failure are presented, that are largely based on the stress components of an individual ply within the laminate. Furthermore, for composite laminates made from layers of unidirectional prepreg tape, failure is classified according to the fibre direction of the ply, with fibre failure occurring in the ply fibre axis and matrix failure occurring in-plane and orthogonal to the fibre axis.

In the failure criteria given: $\sigma, \tau$ and $\varepsilon, \gamma$ are used for stress and strain in the normal and shear directions; $X, Y$, $Z$ and $S$ are strengths in the fibre, matrix, throughthickness directions and shear directions; subscripts 1,2 and 3 refer to the fibre, matrix and through-thickness directions; subscripts $T$ and $C$ denote limit values in tension and compression; subscript is refers to in situ strengths, and all other symbols and abbreviations are explained in the table or in the referenced papers.

In situ strengths are used in a number of failure criteria, though the method for determining these values varies between papers. In situ strengths are used as it has been found experimentally that a ply embedded within a multi-directional laminate has increased transverse tensile and shear strengths as compared to the same ply in a completely unidirectional laminate [18]. This is due to the beneficial effect of the neighbouring plies on damage within an embedded ply, and means that values taken from standardised experimental characterisation coupons, which all use unidirectional coupons, can underestimate actual ply strengths.

One important point for most failure criteria is that they apply at the level of the composite ply. So, limit values such as strength or fracture toughness, though referred to as "material" properties, are actually closer to structural properties given the orthotropic nature of a ply.

Also, for the criteria given, a naming convention has been applied, which uses the year published, the category and the criteria name, where the latter is either the commonly accepted name or the authors of the referenced paper (with et al. used with three or more authors). The categories given cover the range of failure types for a composite ply that are predicted using various criteria. These failure types include fibre failure (fibre), matrix failure (matrix), fibre/matrix failure in shear (shear), general (ply-gen) and interactive (ply-inter) criteria for failure of the entire ply, delamination initiation (delam-init) and delamination growth (delamgrowth), with separate categories for tension (tens) and compression (comp), and a general category (gen) where tension/compression behaviour is not specified. Also, the failure criteria listed are those developed specifically for fibre-reinforced composites, and though many of these were derived from earlier theories developed for metals, these "original" criteria have not been included here due to their limited applicability.

\subsubsection{Fibre Failure}

For composite laminates, fibre failure in tension occurs due to the accumulation of individual fibre failures within plies, which becomes critical when there are not enough intact fibres remaining to carry the required loads. Most authors analysing fibre failure in tension apply a maximum strength or maximum strain criterion at each ply, using simple material limit values taken from experimental testing. Exceptions to this include Hashin [19] who uses a quadratic interaction criterion involving in-plane shear, Chang and Chang [20] who apply the Hashin quadratic interaction criterion but incorporate nonlinear shear behaviour, and Puck and Schürmann [21], who use a maximum strain criterion 
with a stress magnification factor applied to transverse normal stress. In-plane failure criteria for fibre failure in tension are summarised in Table 1.

Fibre failure in compression occurs due to microbuckling and the formation of kink bands, and though there is still debate over whether these phenomena are separate failure modes, microbuckling is a more global failure mode whilst kinking seems to be initiated by local microstructural defects and is the most common failure feature observed after testing [22]. Table 2 gives criteria for compressive fibre failure, where many authors apply the maximum stress or maximum strain criteria using limit values from experimental characterisation, though a number of approaches have been developed for incorporating the effects of microbuckling and kinking.

A number of authors have developed approaches for fibre failure in which the different tension and compression properties of the ply are not specified, combined within the one criterion, or not considered, as summarised in Table 3.

\subsubsection{Matrix Failure}

Matrix failure in laminated composites is a complex phenomenon, in which matrix cracks initiate typically at defects or fibre-matrix interfaces, accumulate throughout the laminate, and coalesce leading to failure across a critical fracture plane. A considerable amount of literature exists on the analysis of matrix cracking and failure, and numerous authors have developed approaches for predicting the initiation of matrix cracks, using fracture mechanics theories to predict the growth or accumulation of damage from existing cracks, and predicting the fracture plane angle under a variety of loading conditions.

Criteria for matrix failure in tension all assume a critical fracture plane in the transverse tension direction, and generally involve an interaction between the tensile normal and in-plane shear stresses. Apart from the maximum stress and maximum strain criteria, the simplest proposal is the quadratic interaction criterion of Hashin and Rotem [23], and further developments include nonlinear shear terms, in situ transverse tensile and shear strengths, incorporating crack density, the use of through-thickness shear and strength terms (in the 23 direction), and the inclusion of fracture mechanics terms from a consideration of a cracked ply, as shown in Table 4. An exception to this is the criterion of Cuntze and
Freund [24], which is only based on the transverse tensile stress and strength and through-thickness shear stress.

The criteria for matrix failure in compression, given in Table 5, are similar to those for tension failure, except that the critical fracture plane is not assumed by all authors. Hashin and Rotem [23] assumed the fracture plane was in the transverse direction (i.e. a fracture plane angle of $0^{\circ}$ ) and proposed a simple quadratic interaction criterion using the transverse normal and in-plane shear components. This was then modified by Hashin [19] to include the through-thickness strength and Chang and Lessard [25] by incorporating a nonlinear shear formulation. In contrast, the criterion of Cuntze and Freund [24] uses only the transverse normal strength, with a combination of several stress invariants. For the criteria considering a non-zero fracture plane angle, this angle must be either assumed or determined by checking all possible angles, though Puck and Schürmann [21] proposed an analytical form for the case of plane stress. It is interesting to note that although matrix compression failure occurs in shear, the fracture plane angle commonly seen in composite laminates is generally $53^{\circ}$ $\pm 2^{\circ}$, which is explained by compressive stress causing friction on the fracture plane [21]. Note that Hashin [19] and Puck and Schürmann [21] also proposed 3D formulations for their respective criteria, though only the 2D forms are given in Table 5.

As shown for fibre failure, some authors have proposed criteria for matrix failure in which the different tension and compression properties of the ply are not specified, combined within the one criterion, or not considered, as summarised in Table 6.

\subsubsection{Shear Failure}

A number of criteria applied in analysing in-plane shear failure are given in Table 7. Although the Hashin [19] 2D criterion was given previously in Table 1 , it is repeated in Table 7 as some authors have used it to analyse fibre-matrix shear failure (see, for example Ref. [25]), or developed improvements for it such as incorporating nonlinear shear or matrix crack density. It is interesting to note that the choice of tension or compression strength is not consistent between papers. Also shown in Table 7 is the criterion of Cuntze and Freund [24], in which the in-plane shear strength is used with a number of stress invariants. 


\subsubsection{Ply Failure}

Several authors have proposed criteria in which the separate ply failure modes are not considered, and failure of the entire ply is predicted. This group includes criteria from papers in which the difference between fibre and matrix failure is either unclear or not specified, given in Table 8, and so-called "fully interactive" criteria such as Tsai-Wu [27], in which all the strength data is used to create a failure surface, usually in stress space, summarised in Table 9. Ply failure criteria are more suited and almost always applied in situations where delamination can be ignored. It is interesting to note that interactive criteria such as Tsai-Wu are often criticised due to their lack of phenomenological basis and origins in theories originally proposed for metals. However, interactive criteria have demonstrated accuracy comparable with leading theories in which the failure modes are considered, and continue to be commonly applied in industry and widely available in FE codes [28].

\subsubsection{Delamination}

A number of criteria have been proposed to predict the initiation of delamination using the stress values of an individual ply or interface element (meshed between plies), and are summarised in Table 10. These criteria all use combinations of the through-thickness tensile and shear parameters, in linear, quadratic or curve-fit relationships, with a small number also considering the stress in the fibre direction. An exception to this is the approach of Wisnom, Hill and Jones [29], which is based on using principal stresses.

Criteria for predicting the growth of a pre-existing delamination are given in Table 11. These criteria are all based on the fracture mechanics concept of a strain energy release rate, $G$, in crack growth, and combine the $G$ components with the threshold $G_{c}$ toughness values in the mode I, II and III directions. For these criteria, $G_{T}$ is the total strain energy release rate found from summing the mode I, II and III components. It is interesting to note the different methods for handling the mode III component. Some authors ignore the contribution or perform 2D analyses considering only modes I and II. Another approach is to combine mode II and mode III components into a $G$ value for shear crack opening. Other authors others treat mode III as acting identically to mode II. This difference are due to a number of reasons, including:: the difficulty in obtaining, identifying and characterising pure mode III crack growth in experiment; the debate over whether mode III constitutes a separate mode or acts together with mode II [30]; and, the absence of any reliable or standardised tests for mixed mode I-III or II-III crack growth [31].

\subsection{Damage Modelling}

Due to the complex nature of laminated composite materials, the onset of damage does not usually lead to ultimate failure, and it is necessary to account for the loss in performance caused by any damage in order to accurately predict composite material performance. Numerous models have been developed to represent the various damage mechanisms and these damage models have been used both in conjunction with and independent of the failure criteria presented in the previous section for damage initiation. A damage mechanics framework, in which the damage developed is used to reduce the material stiffness by introducing a damage model into the material constitutive behaviour, is a common approach that has been applied to both inplane and interlaminar damage. For interlaminar damage, the use of fracture mechanics theories and the introduction of a damageable interface element has been used both with and without damage mechanics theories to represent the inherent structural degradation. The use of a DED function, outlined previously, is a separate approach for characterising laminate damage, which attempts to reflect the nonlinear effects caused by energy dissipation in damage.

\subsubsection{Damage Mechanics}

Damage mechanics is a framework for representing the effects of damage as part of the material definition, and in its general form encompasses most other damage modelling approaches. The application of damage mechanics involves developing equations to represent the initiation and progression of damage mechanisms. These equations are then incorporated into the material constitutive law, and are monitored throughout the analysis. This process typically involves the use of a damage index, which has an inverse relationship to the material properties. Multiple equations can be implemented to represent separate damage mechanisms, or a single damage variable can be used to capture the effects of all damage types. A comprehensive review of damage mechanics theories is given by Talreja [32]. 


\subsubsection{Progressive Ply Damage}

A progressive damage methodology attempts to represent the accumulation of damage in a composite laminate by reducing selected material properties at the ply level. Typically, the structure is loaded until a failure criterion is satisfied, at which point a corresponding material property or property set is reduced, and the analysis is continued. The degraded material property, most commonly stiffness, is selected so as to simulate the loss of load-carrying capacity in a particular direction, and final failure is assumed when a separate condition is satisfied, typically fibre fracture or delamination. Though this approach is simple, the trigger-like knockdown of properties is particularly suited to the quasi-brittle nature of fibre-reinforced composites, and numerous researchers have recorded significant success in applying this approach to represent ply damage mechanisms [28]. Almost all researchers applying a progressive damage methodology have applied a unique combination of failure criteria, degrading action - both property selection and knockdown factor - and final failure condition.

Whilst capable of effectively capturing the reduction of material properties caused by damage, the limitations to a progressive failure approach must be considered. Due to the abundance of easily interchangeable failure criteria, and the efficiency of FE analysis, there is a danger in applying arbitrary or incorrect failure criteria, and then simply using the knockdown factor to "tune" the FE results to produce any desired solution Sound engineering judgment must be applied, so that each damage type being modelled is accurately represented by the failure criteria, and this requires a thorough grasp of the assumptions and limitations of all failure and damage conditions. As Hart-Smith [33] argues, in many cases of progressive failure analysis, damage modes such as matrix cracking and fibre-matrix shearing are applied, with no attempt to correlate any prediction with experimentally observed damage.

\subsubsection{Interface Elements}

Interface elements are separate FE entities, either pointto-point or a continuous element layer, which are modelled between substructures of a composite material as a means of inserting a damageable layer for delamination modelling. Generally, the interface element functions by connecting the two substructures and transferring all tractions across the interface, until a particular criterion is reached, at which point the element stiffness properties degrade. Interface element behaviour is determined by the damage mechanics constitutional relationship between the relative displacement of the two connected substructures, and the traction generated between them as a result. A number of researchers have developed interface elements that utilise a variety of constitutional relationships, some of which are summarised in Table 12 with nomenclature taken from the references. The different models are compared across a few categories, including: type, approach to mixedmode loading, whether additional constants or tests are required, and the types of structures analysed in the paper.

Cohesive elements are a type of interface element that use both damage mechanics and fracture mechanics to define the behaviour of an interface, and are increasingly being applied by researchers to model delaminations and debonds in composite structures. A cohesive zone material model, an example of which is given in Figure 4 , defines the relationship between the gap opening $(\delta)$ and traction $(\tau)$ across the interface. Though a simple bilinear model is shown, numerous authors have developed a range of other relationships such as exponential or linear-exponential. After the element passes the strength limit $\left(\tau_{c}\right)$ of the material, the stiffness is reduced gradually. This continues until the interface has zero stiffness, at which point the substructures are completely separated, and the interface element acts only as a contact region to deny any physically impermissible cross-over of the two substructures. In the cohesive element formulation the work done in reducing the material stiffness to zero is equal to the fracture toughness $\left(G_{c}\right)$. This not only incorporates fracture mechanics theories into the damage mechanics-based approach, but assists in alleviating some of the mesh density problems associated with stress-based analysis.

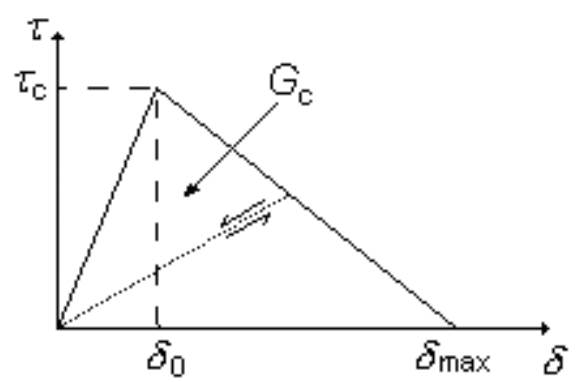

Figure 3: Cohesive zone bilinear material model. 
For delamination and debonding, cohesive elements have a number of important advantages over other modelling approaches, as they have the capacity to investigate both initiation and growth of damage in the same analysis, and to incorporate both strength and fracture mechanics theories. Also, as opposed to classical fracture mechanics, the use of interface elements does not require the assumption of an initial damage size or propagation direction, and obviates the need to apply difficult and computationally expensive re-meshing to accommodate the propagating delamination front. However, cohesive elements require a fine mesh to remain accurate, and can become prohibitively inaccurate when larger mesh sizes are used, which must be considered in application with large structures. Also, the standard cohesive element formulation cannot account for an arbitrary crack front shape and so does not differentiate between shear damage in mode II and III directions, and in general the exact location of the crack front can be difficult to define due to the use of a cohesive-based definition to describe the quasi-brittle nature of composite failure.

\subsubsection{Fracture Mechanics}

Damage modelling for fracture mechanics analysis requires the definition of a pre-existing crack region in the numerical model. For delamination and skin-stiffener debonds, this involves separating the damaged region into two substructures and defining a contact region between them. A number of researchers have also recognised the importance of modelling the entire structure as two separate sublaminates, with a tying connection in the intact region and contact defined in the damage region, to avoid the error involved in fracture mechanics calculations at points of changing thickness [34-35]. However, it is important to note that an intact structure represented as two substructures joined using tying constraints has different bending and interlaminar shear properties compared to a single laminate. In spite of this, the representation of a delamination or debond as a region of separate sublaminates is both necessary for fracture mechanics, and advantageous as it accounts for the structural degradation due to damage.

Accurate damage modelling of delaminations and debonds also requires the damage area to be grown during analysis. Fracture mechanics analysis has been limited in this respect due to the complexities involved in monitoring crack progression and a typical requirement for a fine mesh around the crack front, which usually combine to require either a highly dense mesh or computationally expensive re-meshing. Also, fracture mechanics calculations are generally dependent on the shape of the crack front, particularly the determination of the correct mode mix ratio, and this can require complicated algorithms to monitor the crack front shape as the damage area progresses. These factors have tended to deter researchers from developing fracture mechanics approaches for modelling crack progression, and analyses have been limited to detecting the onset of crack growth only. However, recent approaches have been developed in literature [36], and in the commercial FE codes ABAQUS/Standard [37] and MSC.Marc [38], in which fracture mechanics are used to control the bonding between two contacting surfaces. These approaches all apply VCCT during every increment of a nonlinear analysis, and use single-mode and mixed-mode criteria to determine when attached nodes should be released to represent crack growth. The success of these approaches illustrates that efficient and robust methods are possible for incorporating fracture mechanics into crack propagation analysis.

\subsection{Length Scale}

In order to develop an accurate approach for characterising composite material properties it is important to consider the issues associated with analysis at different length scales [39]. For laminated composite materials there are a number of key length scales, including the sub-ply, ply, laminate, structural detail and component levels. Each of these involves different behaviour and failure mechanisms, and understanding these differences and the interaction between length scales is critical to developing an accurate analysis approach.

For metal structures the consideration of length scale has been less important, as the material and behaviour are generally isotropic, average properties can be used, and the variabilities in the material do not build up on each other. In contrast for composites, the fibre and matrix are fundamentally different materials, and structures are built using variable lay-ups of directionally dependent plies. The damage modes seen in composites are also interactive, where the development of one damage mechanism can delay or intensify the development of others, such as in the stress relaxation of matrix cracking or the structural deformation of delamination buckling.

At the sub-ply level of composites, failure occurs due to interfacial debonding, fibre fracture or matrix cracking 
and analytical models exist for tensile fibre fracture, global load sharing, fibre microbuckling and kink-band formation, matrix cracking and interface debonding. At the ply level, the length scale is the ply thickness, and models exist for fibre tensile and compressive failure and matrix strength, though these are based on empirical factors, and the link back to the sub-ply level is not clear or well defined. At the laminate level, the ply-by-ply failure procedure that is commonly applied is based on ply failure criteria, and again the links back to the ply and sub-ply failure mechanisms are not well defined. At the level of structural detail, the length scales taken include the size of holes, stiffeners, joints, transitions and other structural elements, and the damage mechanisms can be unique to a length scale, which is also true for analysis at a structural component level. This again emphasises the importance of considering the composite as a structure rather than a material in failure analysis.

As a result of these considerations, it is critical to understand the length scales involved in any model and to consider the links and interactions that are important. For composites, the issues of multiple damage sites, manufacturing defects, structural details and probabilistic variation in properties need to be considered. The use of DED has potential in this respect, as it allows the cumulative effect of all nonlinearities measured experimentally to be incorporated into the material constitutive law. Furthermore, DED can act as a bridge in assessing a structural configuration to determine the key length scales, and to investigate suitable test specimens [2].

\section{Discussion}

In order to assess the different approaches for failure predictions and damage modelling, it is necessary to put all considerations within the context of the development of DED. As previously explained, it has been demonstrated that DED can be reliably determined from experimental testing for any material, and measures the cumulative irreversible effects of all damage mechanisms. This has been implemented within an automated, data-driven material characterisation methodology to define the development of damage, and the subsequent loss in material performance, as a function of strain. Current work is aimed at extending this approach to develop a characterisation methodology for composite materials to define behaviour leading up to and including failure. As part of this, it is necessary to consider the range of damage predictions and modelling approaches in literature, in order to highlight approaches that are suitable for predicting composite failure and are applicable within the current DED framework.

Comparing the different failure criteria with each other is a difficult task, which requires extensive experimental data across the full range of possible loading scenarios. The context of failure prediction within a given analysis is also important, particularly the definition of failure or critical failure mechanisms, the level of detail required, size and complexity of the problem, and the availability of material data. This process is further complicated by the vast number of theories and criteria available in literature, the necessary use of curve-fitting or 'tuning' in any analysis to some degree, and the subjective nature of comparison itself.

One notable effort in this regard has been the WorldWide Failure Exercise (WWFE) organised by Hinton, Kaddour and Soden [28]. This exercise spanned 12 years and compared 19 leading failure theories for the analysis of 14 biaxial tests cases covering different materials, laminates and load cases. Numerical predictions were made both without and with access to the experimental data, and the organisers ranked each criterion in a range of categories, including the accuracy of the prediction, necessity for 'tuning' and applicability across the different scenarios. There were some issues with the experimental data concerning the quality, relevance and completeness of the results. In spite of this, the exercise was highly valuable in assessing the state of the art and highlighting key strengths and weaknesses of current approaches. As a result of the exercise, five methods for failure prediction were identified as promising: Puck [21], Zinoviev (a Maximum Stress approach), Tsai [27], Cuntze [24] and Bogetti (a 3D Maximum Strain approach). Predictions were compared at a lamina level and for multi-directional laminates, and it was seen that even the most accurate theories only predicted the final fracture strength of the multi-directional laminates within $\pm 50 \%$ for $85 \%$ of the test cases. Two further exercises are currently planned, WWFE-II [40] and WWFE-III [41], to address shortcomings in current composite failure theories in considering triaxial loadings and dealing with damage and associated modelling techniques.

In terms of applicability within the framework of DED, most failure theories and criteria are suitable in this respect due to their operation within the stress space. The DED approach has been incorporated into a fully 
nonlinear constitutive behaviour, which describes a stress-strain relationship that is a dependent on the DED function, which itself is similar to a characterised material property [1]. In this manner, most criteria can be applied in combination with the DED framework, in terms of monitoring and representing failure throughout the analysis.

Furthermore, in a companion paper [42] it is shown that various criteria can be reduced to one another, and that under specific conditions most failure criteria and theories are actually constrained renderings of criteria based on energy density. This type of construction allows current failure theories to be reformulated within energy density terms, and is further detailed in Ref. [42].

In order to be consistent with the application of DED within the constitutive relationship, it may be more suitable to simply monitor various failure criteria to predict final failure. This type of analysis would be dependent on completely characterising the DED function in all six DOF up until failure. A 6DOF DED function would obviate the need for any further damage modelling, such as ply damage or delamination modelling, as all damage types would implicitly be included within the DED function. A fully automated 6DOF testing machine developed at NRL for this purpose [2] will be applied to investigate irreversible damage development under a wide of loading conditions up until and including failure.

\section{Conclusion}

A review has been conducted of methodologies for modelling constitutive behaviour and failure in fibrereinforced polymer composites. This review was part of a project to extend an approach developed at NRL for data-driven characterisation of composite material systems that is based on the application of DED. Methods for constitutive modelling were reviewed, and were classified as either explicit, implicit or hybrid, depending on the extent to which physically-based theories were used to describe the material stress-strain behaviour. The failure mechanisms of fibre fracture, matrix cracking, buckling and delamination were listed as the key damage mechanisms for a composite ply in a laminate. The characterisation of composite failure in terms of strength or fracture mechanics theories was covered, with reference to the methods for experimentally determining material limits.
A comprehensive review of failure criteria was presented, where criteria were categorised in terms of the failure type predicted, which included fibre, matrix, shear, ply, delamination initiation and delamination growth, with separate categories for tension, compression and general equations. This was followed by a review of common methods for damage modelling, which were all shown to relate to the concept of damage mechanics, in which damage equations are incorporated in the material constitutive behaviour. The issues of length scale were discussed, which is critical for an analysis approach to apply from scales ranging from the ply to the structural level.

The various failure criteria and modelling approaches were discussed within the context of the DED framework. The difficult task of comparing failure criteria to each other was discussed, and the notable work of the WWFE in this regard was highlighted. It was found that most criteria could be applied in combination with the DED approach, due to the incorporation of the DED function within the material stress-strain behaviour. Furthermore, the reducibility of failure criteria under certain conditions was noted, as was the direct relationship of most criteria to criteria based on energy density. The benefits of the successful application of a 6DOF material characterisation approach were discussed, and reference was made to the 6DOF loading machine developed at NRL.

\section{Acknowledgements}

The authors kindly acknowledge the financial support of the US Office of Naval Research under NICOP grant N00014-07-1-0514. The assistance of Dr John Michopoulos of NRL, Prof. Paul Lagacé of MIT and Dr Alan Baker of the CRC-ACS is also gratefully acknowledged.

\section{References}

1. Mast, PW, Nash, GE, Michopoulos, JG, Thomas, R, Badaliance, R \& Wolock, I 1995, 'Characterization of strain-induced damage in composites based on the dissipated energy density: Part I to III', Theoretical and Applied Fracture Mechanics, vol. 22, pp. 71-125.

2. Michopoulos JG, Badaliance R, Chwastyk T, Gause L, Mast P. Effects of computational technology on composite materials research: The case of the dissipated energy density. In: 
Proceedings of the First Hellenic Conference on Composite Materials and Structures, 2-5 July 1997, Greece.

3. Michopoulos, JG 2004, 'Mechatronically automated characterization of material constitutive response', in Computational Mechanics WCCM VI in conjunction with APCOM’04, 5-10 September, Beijing, China.

4. Ochoa, OO \& Reddy, JN 1992, Finite Element Analysis of Composite Laminates, Kluwer Academic Publishers, Dordrecht, The Netherlands.

5. Galiotis, C \& Paipetis, A 2005, 'Interfacial damage modelling of composites', in Multi-scale modelling of composite material systems, Soutis, C \& Beaumont, PWR (eds), Woodhead Publishing Limited, Cambridge, England.

6. Baker, AA, Dutton, S \& Kelly, DW (eds) 2004, Composite Materials for Aerospace Structures, 2nd ed., AIAA, Virginia, USA.

7. Furukawa, $\mathrm{T}$ \& Yagawa, G 1998, 'Implicit constitutive modelling for viscoplasticity using neural networks' International Journal for Numerical Methods in Engineering, vol. 43, pp. 195-219.

8. Hashash, YMA, Jung, S \& Ghaboussi, J 2004, 'Numerical implementation of a neural network based material model in finite element analysis', International Journal For Numerical Methods In Engineering, vol. 59, pp. 989-1005.

9. Man, H \& Furukawa, $T$ 2007, 'An indirect implicit technique for modelling piezoelectric ceramics', Computational Materials Science, (submitted April 2007).

10. Ghaboussi, J, Pecknold, DA, Zhang, M \& HajAli, RM 1998, 'Autoprogressive training of neural network constitutive models', International Journal for Numerical Methods in Engineering, vol. 42, pp. 105-126.

11. Haj-Ali, RM \& Kim, H-K 2007, 'Nonlinear constitutive models for FRP composites using artificial neural networks', Mechanics of Materials, doi:10.1016/j.mechmat.2007.05.004.

12. Huang, H, Springer, GS \& Christensen, RM 2006, 'Predicting failure in composite laminates using dissipated energy', Journal of Composite Materials, vol. 37, no. 23, pp. 2073-2099.

13. Banks-Sills, L 1991, 'Application of the finite element method to linear elastic fracture mechanics', Applied Mechanics Reviews, vol. 44, pp. 447-461.
14. Rybicki, EF \& Kanninen, MF 1977, 'A finite element calculation of stress intensity factors by a modified crack closure integral', Engineering Fracture Mechanics, vol. 9, pp. 931-938.

15. Davidson, BD, Hu, H \& Hongwei, Y 1996, 'An efficient procedure for determining mixed-mode energy release rates in practical problems of delamination', Finite Elements in Analysis and Design, vol. 23. pp. 193-210.

16. Furukawa, T \& Michopoulos, JG 2005, 'Computational Design of Multiaxial Tests for Anisotropic Material Characterization', International Journal For Numerical Methods In Engineering, (paper accepted).

17. Furukawa, T \& Michopoulos, JG 2007, 'Online Planning of Multiaxial Loading Path for Elastic Material Identification', Computer Methods in Applied Mechanics and Engineering, doi:10.1016/j.cma.2007.05.027.

18. Dávila, CG \& Camanho, PP 2003, Failure criteria for FRP laminates in plane stress, NASA/TM-2003-212663, NASA Langley Research Center, Virginia, USA.

19. Hashin, Z 1980, 'Failure criteria for unidirectional composites', Journal of Applied Mechanics, vol. 47, pp. 329-334.

20. Chang, F-K \& Chang, K-Y 1987, 'A progressive damage model for laminated composites containing stress concentrations', Journal of Composite Materials, vol. 21, pp. 834-855.

21. Puck, A \& Schürmann, H 1998, 'Failure analysis of FRP laminates by means of physically based phenomenological models', Composites Science and Technology, vol. 58, pp. 1045-1067.

22. Pinho, ST, Dávila, CG, Camanho, PP, Iannucci, L \& Robinson, P 2005, Failure models and criteria for FRP under in-plane or threedimensional stress states including shear nonlinearity, NASA/TM-2005-213530, NASA Langley Research Center, Virginia, USA.

23. Hashin, Z \& Rotem, A 1973, 'A fatigue failure criterion for fiber reinforced materials', Journal of Composite Materials, vol. 7, pp. 448-464.

24. Cuntze, RG \& Freund, A 2004, 'The predictive capability of failure mode concept-based strength criteria for multidirectional laminates', Composites Science and Technology, vol. 64, pp. 344-377.

25. Chang, F-K \& Lessard, LB 1991, 'Damage tolerance of laminated composites containing an open hole and subject to compressive loadings: 
part I - analysis', Journal of Composite Materials, vol. 25, pp. 2-43.

26. Goyal, VK, Johnson, ER \& Dávila, CG 2004, 'Irreversible constitutive law for modelling the delamination process using interfacial surface discontinuities', Composite Structures, vol. 65, no. 3-4, pp. 289-305.

27. Tsai, SW \& Wu, EM 1971, 'A general theory of strength for anisotropic materials', Journal of Composite Materials, vol. 5, pp. 58-80.

28. Hinton, MJ, Kaddour, AS \& Soden, PD 2004, Failure Criteria in Fibre Reinforced Polymer Composites, Elsevier, Amsterdam, The Netherlands.

29. Wisnom, MR, Hill, GFJ \& Jones, MI 2001, 'Through thickness failure prediction of composite structural elements', in 13th International Conference on Composite Materials, Beijing, China, paper no. 1623.

30. Camanho, PP \& Dávila, CG 2002, Mixed-mode decohesion finite elements for the simulation of delamination in composite materials, NASA/TM-2002-211737, NASA Langley Research Center, Virginia, USA.

31. O’Brien, TK 1998, 'Interlaminar fracture toughness: The long and winding road to standardization', Composites: Part B, vol. 29, pp. 57-62.

32. Talreja R. Damage mechanics of composite materials. Composite Materials Series, vol. 9. Oxford (UK): Elsevier Science Ltd.; 1994

33. Hart-Smith, LJ 1998, 'Predictions of the original and truncated maximum-strain failure models for certain fibrous composite laminates', Composites Science and Technology, vol. 58, pp. 1151-1178.

34. Bruno, D \& Greco, F 2001, 'Mixed mode delamination in plates: a refined approach', International Journal of Solids and Structures, vol. 38, pp. 9149-9177.

35. Wang, JT \& Qiao, P 2004, 'On the energy release rate and mode mix of delaminated shear deformable composite plates', International Journal of Solids and Structures, vol. 41, pp. 2757-2779.

36. Orifici, AC 2007, 'Degradation models for the collapse analysis of composite aerospace structures', PhD thesis, Royal Melbourne Institute of Technology.

37. VCCT for ABAQUS User's Manual, Version 1.1 2005, ABAQUS, Inc., Rhode Island, USA.
38. MSC. Marc User Manuals Version 2005r3 2006, MSC.Software Corporation, Santa Ana, California.

39. Spearing MS, Lagacé PA, McManus HLN. On the role of lengthscale in the prediction of failure of composite structures: Assessment and needs. Appl Compos Mat 1998;5:139-49.

40. Hinton MJ, Kaddour AS. The second worldwide failure exercise: Benchmarking of failure criteria under triaxial stresses for fibrereinforced polymer composites. In: Proceedings of the 16th International Conference on Composite Materials, 8-13 July 2007, Kyoto, Japan.

41. Kaddour AS, Hinton MJ, Li S, Smith PA. Damage theories for fibre-reinforced polymer composites: The third world-wide failure exercise (WWFE-III). In: Proceedings of the 16th International Conference on Composite Materials, 8-13 July 2007, Kyoto, Japan.

42. Michopoulos, JG. Semantic and syntactic reducibility of failure theories for composite materials and structures. In: Proceedings of the 14th International Conference on Composite Structures, 19-21 November 2007, Melbourne, Australia.

43. Greszczuk, LB 1974, 'Microbuckling of laminareinforced composites", Composite Materials: Testing and Design (Third Conference), ASTM STP 546, American Society for Testing and Materials, pp. 5-29.

44. Maimì, P, Camanho, PP, Mayugo, JA \& Dávila, CG, 'A continuum damage model for composite laminates: Part I Eutivé omstidel', Mechanics of Materials, vol. 39, pp. 897-908.

45. Lee, JD 1982, 'Three dimensional finite element analysis of damage accumulation in composite laminate', Computers \& Structures, vol. 15 no. 33, pp. 335-350.

46. Christensen, RM 1997, 'Stress based yield/failure criteria for fiber composites', International Journal of Solids and Structures, vol. 34, no. 5, pp. 529-543.

47. Huang, H, Springer, GS \& Christensen, RM 2006, 'Predicting failure in composite laminates using dissipated energy', Journal of Composite Materials, vol. 37, no. 23, pp. 2073-2099.

48. Ladeveze, P \& Le Dantec, E 1992, 'Damage modelling of the elementary ply for laminated composites', Composites Science and Technology, vol. 43, pp. 257-267. 
49. Shahid, I \& Chang, F-K 1995, 'An accumulative damage model for tensile and shear failures of laminated composite plates', Journal of Composite Materials, vol. 29, no. 7, pp. 926981.

50. Gosse, JH \& Christensen, S 2001, Strain invariant failure criteria for polymers in composite materials, AIAA paper, AIAA-20011184.

51. Sandhu, RS 1974, Ultimate strength analysis of symmetric laminates, AFFDL-TR-73-137, AD 779927, Air Force Flight Dynamics Laboratory, Wright-Patterson Air Force Base, $\mathrm{OH}$.

52. Yamada, SE \& Sun, CT 1978, 'Analysis of laminate strength and its distribution', Journal of Composite Materials, vol. 12, pp. 275-284.

53. Christensen, RM 1988, 'Tensor transformations and failure criteria for the analysis of fiber composite materials' Journal of Composite Materials, vol. 22, pp. 874-897.

54. Hill, R 1948, 'A theory of the yielding and plastic flow of anisotropic metals', Proceedings of the Royal Society of London, Series A, vol. 193, pp. 281-297.

55. Tsai, SW 1965, Strength Characteristics of Composite Materials, NASA CR-224.

56. Hoffman, O 1967, 'The brittle strength of orthotropic materials', Journal of Composite Materials, vol. 1, pp.200-206.

57. Tsai, SW \& Wu, EM 1971, 'A general theory of strength for anisotropic materials', Journal of Composite Materials, vol. 5, pp. 58-80.

58. Theocaris, PS 1992, 'Weighing failure tensor polynomial criteria for composites', International Journal of Damage Mechanics, vol. 1, pp 4-46.

59. Kim, CH \& Yeh, H-Y 1994, 'Development of a new yielding criterion: the Yeh-Stratton criterion', Engineering Fracture Mechanics, vol. 47, pp. 569-582.

60. Echaabi, J \& Trochu, F 1997, 'Failure mode dependent strength criteria for composite laminates', Journal of Reinforced Plastics and Composites, vol. 16, no. 10, pp. 926-945.

61. Kim, RY \& Soni, SR 1986, 'Failure of composite laminates due to combined interlaminar normal and shear stresses', in Kawata, K, Umekawa, S \& Kobayashi, A (eds) Composites '86: Recent Advances in Japan and the United States, Proceedings of Japan-U.S. CCM-III, pp. 341-350.
62. Ochoa, OO \& Engblom, JJ 1987, 'Analysis of progressive failure in composites', Composites Science and Technology, vol. 28, pp. 87-102.

63. Brewer, JC \& Lagacé, PA 1988, 'Quadratic stress criterion for initiation of delamination', Journal of Composite Materials, vol. 22, pp. 1141-1155.

64. Long, RS, 1991, 'Static strength of adhesively bonded ARALL-1 joints', Journal of Composite Materials, vol. 25, pp. 391-415.

65. Tong, L 1997, 'An assessment of failure criteria to predict the strength of adhesively bonded composite double lap joints', Journal of Reinforced Plastics and Composites, vol. 16, no. 8, pp. 698-713.

66. Zhang, X 1998, 'Impact damage in composite aircraft structures

numerical simulation', Journal of Aerospace Engineering, vol. 212 no. 4, pp. 245-259.

67. Hahn, HT 1983, 'A mixed-mode fracture criterion for composite materials', Composites Technology Review, vol. 5, pp. 26-29.

68. Hahn, HT \& Johnnesson, T 1983, 'A correlation between fracture energy and fracture morphology in mixed-mode fracture of composites', in Mechanical Behaviour of Materials - IV, Stockholm, pp. 431-438.

69. Whitcomb, JD 1984, Analysis of InstabilityRelated Growth of a Through-Width Delamination, NASA TM-86301.

70. Donaldson, SL 1985, 'Fracture toughness testing of graphite/epoxy and graphite/peek composites', Composites, vol. 16. no. 2, pp. 103112.

71. Hashemi, S \& Kinloch, AJ 1987, 'Interlaminar fracture of composite materials', in 6th ICCM \& 2nd ECCM, Matthews, FL et al. (eds), Elsevier Applied Science, New York, pp. 254-264.

72. White, SR 1987, 'Mixed-mode interlaminar fracture of graphite/epoxy', Washington University.

73. Hashemi-Kinloch, S \& Kinloch, AJ 1990, 'The effect of geometry, rate and temperature on the mode I, mode II and mixed-mode I/II interlaminar fracture of carbon-fibre/poly(etherether ketone) composites', Journal of Composite Materials, vol. 24, pp. 918-956.

74. Yan, XQ, Du, SY \& Wang, DUO 1991, 'An engineering method of determining the delamination fracture toughness of composite 
laminates’ Engineering Fracture Mechanics, vol. 39, no. 4, pp. 623-627.

75. Hashemi, S \& Williams, JG 1991, 'Mixed-mode fracture in fiber-polymer composite laminates', in O'Brien, TK (ed.), Composite Materials: Fatigue and Fracture, Vol. 3, ASTM STP 1110, ASTM Int., W. Conshohocken, PA.

76. Reeder, JR 1993, 'A bilinear failure criterion for mixed-mode delamination', in Componeschi Jr, ET (ed.), Composite Materials: Testing and Design (Eleventh Volume), ASTM STP 1206, ASTM Int., W. Conshohocken, PA, pp. 303-322.

77. Benzeggagh, ML \& Kenane, M 1996, 'Measurement of mixed-mode delamination fracture toughness of unidirectional glass/epoxy composites with mixed-mode bending apparatus', Composites Science and Technology, vol. 56, pp. 439-449.

78. Davidson, BD \& Zhao, W 2007, 'An accurate mixed-mode delamination failure criterion for laminated fibrous composites requiring limited experimental input', Journal of Composite Materials, vol. 41, no. 6, pp. 679-702.

79. Cui, W \& Wisnom, MR 1993, 'A combined stress-based and fracture mechanics-based model for predicting delamination in composites', Composites, vol. 24, pp. 467-474.

80. Hachenberg, D \& Kossira, H 1993, 'Stringer peeling effects at stiffened composite panels in the postbuckling range', Journal of Aircraft, vol. 30, no. 5, pp. 769-776.

81. Schellekens, JCJ \& de Borst, R 1993, 'A nonlinear finite element approach for the analysis of Mode-I free edge delamination in composites', International Journal of Solids and Structures, vol. 30, pp. 1239-1253.

82. Reedy Jr, ED, Mello FJ \& Guess, TR 1997, 'Modelling the initiation and growth of delaminations in composite structures', Journal of Composite Materials, vol. 31, no. 8, pp. 812831.

83. Mi, Y, Crisfield, MA, Davies, GAO \& Hellweg, HB 1998, 'Progressive delamination using interface elements', Journal of Composite Materials, vol. 32, no. 14, pp. 1246-1272.

84. Petrossian, Z \& Wisnom, MR 1998, 'Prediction of delamination initiation and growth from discontinuous plies using interface elements', Composites: Part A, vol. 29A, pp. 503-515.
85. Wisheart, M \& Richardson, MOW 1998, 'The finite element analysis of impact induced delamination in composite materials using a novel interface element', Composites: Part A, vol. 29A, pp. 301-313.

86. de Moura, MFSF, Gonçalves, JPM, Marques, AT \& de Castro, PMST 2000, 'Prediction of compressive strength of carbon-epoxy laminates containing delamination by using a mixed-mode damage model', Composite Structures, vol. 50, pp. 151-157.

87. Jansson, E \& Larsson, $\mathrm{R}$ 2001, 'A damage model for simulation of mixed-mode delamination growth', Composite Structures, vol. 53, pp. 409-417.

88. Qiu, Y, Crisfield, MA \& Alfano, G 2001, 'An interface element formulation for the simulation of delamination with buckling', Engineering Fracture Mechanics, vol. 68, pp. 1755-1776.

89. Borg, R, Nilsson, L \& Simonsson, K 2001, 'Simulation of delamination in fiber composites with a discrete cohesive failure model', Composites Science and Technology, vol. 61, pp. 667-677.

90. Zou, Z, Reid, SR, Li, S \& Soden, PD 2002, 'Application of a delamination model to laminated composite structures', Composite Structures, vol. 56, pp. 375-389.

91. Zou, Z, Reid, SR \& Li, S 2003, 'A continuum damage model for delaminations in laminated composites', Journal of the Mechanics and Physics of Solids, vol. 51, pp. 333-356. 


\section{Tables}

Table 1: Failure criteria for fibre failure in tension

\begin{tabular}{|c|c|c|}
\hline Criterion & Equation & Additional terms \\
\hline Max-stress_fibre-tens & $\sigma_{1} \geq X_{T}$ & \\
\hline Max_strain_fibre-tens & $\varepsilon_{1} \geq \varepsilon_{1 T}$ & \\
\hline $\begin{array}{l}\text { 1980_Hashin-3D } \\
\text { _fibre-tens [19] }\end{array}$ & $\left(\frac{\sigma_{1}}{X_{T}}\right)^{2}+\frac{1}{S_{12}{ }^{2}}\left(\tau_{12}{ }^{2}+\tau_{13}{ }^{2}\right) \geq 1$ & \\
\hline $\begin{array}{l}\text { 1980_Hashin-2D } \\
\text { _fibre-tens [19] }\end{array}$ & $\left(\frac{\sigma_{1}}{X_{T}}\right)^{2}+\left(\frac{\tau_{12}}{S_{12}}\right)^{2} \geq 1$ & \\
\hline $\begin{array}{l}\text { 1987_Chang-Chang } \\
\text { _fibre-tens [20] }\end{array}$ & $\sqrt{\left(\frac{\sigma_{1}}{X_{T}}\right)^{2}+\frac{\frac{\tau_{12}{ }^{2}}{2 G_{12}}+\frac{3}{4} \alpha \tau_{12}{ }^{4}}{\frac{\bar{S}_{12}{ }^{2}}{2 G_{12}}+\frac{3}{4} \alpha \bar{S}_{12}{ }^{4}}} \geq 1$ & $\begin{array}{l}\alpha \text { from nonlinear shear law } \\
\gamma_{12}=\left(\frac{1}{G_{12}}\right) \tau_{12}+\alpha \tau_{12}{ }^{3}\end{array}$ \\
\hline $\begin{array}{l}\text { 1998_Puck } \\
\text { _fibre-tens [21] }\end{array}$ & $\frac{1}{\varepsilon_{1 T}}\left(\varepsilon_{1}+\frac{v_{f 12}}{E_{f 1}} m_{f \sigma} \sigma_{2}\right) \geq 1$ & $\begin{array}{l}\text { subscript } f \text { denotes fibre values } \\
m_{f \sigma}: \text { stress magnification factor }\end{array}$ \\
\hline
\end{tabular}


Table 2: Failure criteria for fibre failure in compression

\begin{tabular}{|c|c|c|}
\hline Criterion & Equation & Additional terms \\
\hline $\begin{array}{l}\text { Max-stress } \\
\text { fibre-comp }\end{array}$ & $\sigma_{1} \geq X_{C}$ & \\
\hline $\begin{array}{l}\text { Max_strain } \\
\text { fibre-comp }\end{array}$ & $\varepsilon_{1} \geq \varepsilon_{1 C}$ & \\
\hline $\begin{array}{l}\text { 1974_Greszczuk } \\
\text { fibre-comp [43] }\end{array}$ & $\sigma_{1} \geq \frac{G_{12}^{m}}{1-V_{f}}$ & $\begin{array}{l}G_{12}{ }^{m}: \text { matrix shear modulus } \\
V_{f}: \text { fibre volume fraction }\end{array}$ \\
\hline $\begin{array}{l}\text { 1991_Chang-Lessard } \\
\text { fibre-comp [25] }\end{array}$ & $\sigma_{1} \geq \bar{X}_{C}$ & $\begin{array}{l}\bar{X}_{C}: \text { microbuckling strength, } \\
\text { equation in separate paper }\end{array}$ \\
\hline $\begin{array}{l}\text { 1998_Puck } \\
\text { fibre-comp [21] }\end{array}$ & $\frac{1}{\varepsilon_{1 C}}\left|\left(\varepsilon_{1}+\frac{v_{f 12}}{E_{f 1}} m_{f \sigma} \sigma_{2}\right)\right| \geq 1-\left(10 \gamma_{21}\right)^{2}$ & $\begin{array}{l}\text { subscript } f \text { denotes fibre values } \\
m_{f \sigma}: \text { stress magnification factor }\end{array}$ \\
\hline $\begin{array}{l}\text { 2003_LaRC03 } \\
\text { fibre-comp [18] }\end{array}$ & $\begin{array}{l}\text { for } \sigma_{22}{ }^{m}<0:\left\langle\frac{\left|\tau_{12}{ }^{m}\right|+\eta_{12} \sigma_{22}{ }^{m}}{S_{12 i s}}\right\rangle \geq 1 \\
\text { for } \sigma_{22}{ }^{m}>0: \\
(1-g)\left(\frac{\sigma_{22}{ }^{m}}{Y_{T i s}}\right)+g\left(\frac{\sigma_{22}{ }^{m}}{Y_{T i s}}\right)^{2}+\left(\frac{\tau_{12}{ }^{m}}{S_{12 i s}}\right)^{2} \geq 1\end{array}$ & $\begin{array}{l}\sigma_{22}{ }^{m}, \tau_{12}{ }^{m} \text { : stresses in 2D kinking } \\
\text { frame, at angle } \varphi \\
g=G_{I_{c}} / G_{I I c} \text { different for thin and } \\
\text { thick plies }\end{array}$ \\
\hline $\begin{array}{l}\text { 2005_LaRC04 } \\
\text { fibre-comp [22] }\end{array}$ & $\begin{array}{l}\text { for } \sigma_{2 m_{2} m}<0, \frac{\left|\tau_{1 m_{2 m}}\right|}{S_{12 i s}-\eta_{12} \sigma_{2^{m} 2^{m}}} \geq 1 \\
\text { for } \sigma_{2 m_{2} m}>0,(1-g)\left(\frac{\sigma_{2^{m_{2} m}}}{Y_{T i s}}\right)+ \\
g\left(\frac{\sigma_{2^{m} 2^{m}}}{Y_{T i s}}\right)^{2}+\frac{\Lambda_{23}{ }^{0} \tau_{2^{m}{ }_{3} \varphi}{ }^{2}+\chi\left(\gamma_{1^{m} 2^{m}}\right)}{\chi\left(\gamma_{12 i s}{ }^{u}\right)} \geq 1\end{array}$ & $\begin{array}{l}\sigma_{2^{m} 2^{m}}, \tau_{1{ }^{m} 2^{m}}, \tau_{23}{ }^{m}, \tau_{12}{ }^{m}, \sigma_{3}{ }^{m}, \\
\tau_{2 m_{3} \varphi} \text { are stresses in 3D kinking } \\
\text { frame, at angles } \varphi, \psi \\
g=G_{I_{c}} / G_{I I c} \text { different for thin and } \\
\text { thick plies } \\
\text { 3D kinking angles found by } \\
\text { iteration; if no solution found failure } \\
\text { is due to instability }\end{array}$ \\
\hline $\begin{array}{l}\text { 2007_Maimí-et-al } \\
\text { _fibre-comp [44] }\end{array}$ & $\left\langle\left|\tau_{12}{ }^{m}\right|+\eta_{12} \sigma_{22}{ }^{m}\right\rangle / S_{12} \geq 1$ & $\begin{array}{l}\sigma_{22}{ }^{m}, \tau_{12}{ }^{m} \text { : stresses in 2D kinking } \\
\text { frame, at angle } \varphi^{C}\end{array}$ \\
\hline
\end{tabular}


Table 3: Failure criteria for fibre failure in tension and compression

\begin{tabular}{lll}
\hline Criterion & Equation & Additional terms \\
\hline $\begin{array}{l}\text { 1982_Lee } \\
\text { fibre-gen [45] }\end{array}$ & $\sigma_{1} \geq \sigma_{F N}$ or & $\begin{array}{l}\sigma_{F N} \text { : fibre normal strength } \\
\sigma_{F S} \text { : fibre in-plane shear strength }\end{array}$ \\
\hline $\begin{array}{l}\text { 1997_Christensen } \\
\text { fibre-gen [46] }\end{array}$ & $\alpha_{2} k_{2} \sigma_{1}+\frac{1}{4}\left(1+2 \alpha_{2}{ }^{2}\right)$ & $\sigma_{1}{ }^{2}$ \\
& $-\frac{\left(1+\alpha_{2}\right)^{2}}{2} \frac{\left(\sigma_{2}+\sigma_{3}\right)}{2} \sigma_{1} \leq k_{2}{ }^{2}$ & $k_{2}=\frac{X_{T}}{2}, \alpha_{2}=\frac{1}{2}\left(\frac{X_{T}}{\left|X_{C}\right|}-1\right)$ \\
\hline $\begin{array}{l}\text { 2003_Huang-et-al } \\
\text { fibre-gen [47] }\end{array}$ & $\begin{array}{l}\text { use dissipated energy density } \phi(\varepsilon) \\
\text { to indicate damage: } \\
\text { fibre failure for } \phi(\varepsilon)>D_{t}\end{array}$ & $\begin{array}{l}D_{t}=\text { dissipated energy density } \\
\text { threshold }\end{array}$ \\
\hline
\end{tabular}


Table 4: Failure criteria for matrix failure in tension

\section{Criterion}

Max-stress_matrix-tens

Max_strain_matrix-tens

1973_Hashin-Rotem

matrix-tens [23]

1980_Hashin-3D

matrix-tens [19]

1987_Chang-Chang

_matrix-tens [20]

1991_Chang-Lessard matrix-tens [25]

1992_Ladeveze _matrix-tens [48]

\section{Equation}

$\sigma_{2} \geq Y_{T}$

$\varepsilon_{2} \geq \varepsilon_{2 T}$

$\left(\sigma_{2} / Y_{T}\right)^{2}+\left(\tau_{12} / S_{12}\right)^{2} \geq 1$

$\frac{\left(\sigma_{2}+\sigma_{3}\right)^{2}}{Y_{T}{ }^{2}}+\frac{\tau_{23}{ }^{2}-\sigma_{2} \sigma_{3}}{S_{23}{ }^{2}}+\frac{\tau_{12}{ }^{2}-\tau_{13}{ }^{2}}{S_{12}{ }^{2}} \geq 1$

\section{Additional terms}
$\alpha$ from nonlinear shear
$\gamma_{12}=\tau_{12} / G_{12}+\alpha \tau_{12}{ }^{3}$
$\sqrt{\left(\frac{\sigma_{2}}{Y_{T}}\right)^{2}+\frac{\tau_{12}{ }^{2} / 2 G_{12}+\frac{3}{4} \alpha \tau_{12}{ }^{4}}{S_{12 \text { is }}{ }^{2} / 2 G_{12}+\frac{3}{4} \alpha S_{12 \text { is }}{ }^{4}}} \geq 1$

Chang and Chang (1987) with in situ strength $Y_{T \text { is }}$ instead of $Y_{T}$

use $d_{2}, \bar{\Psi}_{2}$ to indicate damage:

total failure for $d_{2} \geq 1 \quad \bar{\Psi}_{2} \geq \Psi_{2 \max }$

$d_{2}=\left\langle\bar{\Psi}_{2}-\Psi_{2 \text { init }}\right\rangle_{+} / \Psi_{2 \text { crit }}$

$\bar{\Psi}_{2}(t)=\sqrt{\frac{1}{2} \frac{\left\langle\sigma_{2}\right\rangle_{+}{ }^{2}}{E_{2}\left(1-d_{2}\right)^{2}}}$ and $\bar{\Psi}_{2}=\max \bar{\Psi}_{2}(t)$

$\left(\frac{\bar{\sigma}_{2}}{Y_{T}(\phi)}\right)^{2}+\left(\frac{\bar{\tau}_{12}}{S_{12}(\phi)}\right)^{2} \geq 1$

$\sqrt{\left(\tau_{21} / S_{21}\right)^{2}+\left(1-p_{\perp \|}{ }^{(+)} Y_{T} / S_{21}\right)^{2}\left(\sigma_{2} / Y_{T}\right)^{2}}$

$+p_{\perp \|}{ }^{(+)} \sigma_{2} / S_{21} \geq 1-\left|\sigma_{1} / \sigma_{1 D}\right|$

2003_LaRC03

_matrix-tens [18]

$(1-g)\left(\frac{\sigma_{2}}{Y_{T \text { is }}}\right)+g\left(\frac{\sigma_{2}}{Y_{T \text { is }}}\right)^{2}+\left(\frac{\tau_{12}}{S_{12 \text { is }}}\right)^{2} \geq 1$

$\left[I_{2}+\sqrt{I_{4}}\right] / 2 Y_{T} \geq 1$

$I_{2}=\sigma_{2}+\sigma_{3}, I_{4}=\left(\sigma_{2}-\sigma_{3}\right)^{2}+4 \tau_{23}{ }^{2}$

2005_LaRC04

$$
(1-g)\left(\frac{\sigma_{2}}{Y_{\text {Tis }}}\right)+g\left(\frac{\sigma_{2}}{Y_{\text {Tis }}}\right)^{2}+\frac{\Lambda_{23}{ }^{0} \tau_{23}{ }^{2}+\chi\left(\gamma_{12}\right)}{\chi\left(\gamma_{12 \text { is }}{ }^{u}\right)} \geq 1
$$

$g=G_{I c} / G_{I I c}$, different for thin and thick plies

$$
\begin{aligned}
& \sigma_{2} \geq 0: \sqrt{(1-g)\left(\frac{\sigma_{2}}{Y_{T}}\right)+g\left(\frac{\sigma_{2}}{Y_{T}}\right)^{2}+\left(\frac{\tau_{12}}{S_{12}}\right)^{2}} \geq 1 \\
& \sigma_{2}<0:\left\langle\left|\tau_{12}\right|+\eta_{12} \sigma_{2}\right\rangle / S_{12} \geq 1
\end{aligned}
$$

$\langle a\rangle_{+}=a$ if $a \geq 0$, else 0

$\Psi_{2 \text { init }}$, crit, ${ }_{\text {max }}$ : material parameters

from tension test on $[ \pm 67.5]_{2 \mathrm{~S}}$

coupon

Also uses plasticity law

$\bar{\sigma}$ : effective ply stresses

$\phi$ : matrix crack density

$Y_{T}, S_{12 \text { : }}$ use crack density

$p_{\perp \|}{ }^{(+)}=-\left(d \tau_{21} / d \sigma_{2}\right)_{\sigma_{2}=0}$

$\sigma_{1 D}$ is stress value for linear degradation $g=G_{I_{C}} / G_{I I C}$, different for thin and thick plies _matrix-tens [22]

2007_Maimí-et-al _matrix-tens [44]

2004_Cuntze

_matrix-tens [24] 
Table 5: Failure criteria for matrix failure in compression

\section{Criterion}

Equation

Max-stress_matrix-comp

Max_strain_matrix-comp

1973_Hashin-Rotem

_matrix-comp [23]

1980_Hashin-2D

_matrix-comp [19]

1991_Chang-Lessard

_matrix-comp [25]

1998_Puck

_matrix-comp [21]

$\sigma_{2} \geq Y_{C}$

$\varepsilon_{2} \geq \varepsilon_{2 C}$ $\left(\sigma_{2} / Y_{C}\right)^{2}+\left(\tau_{12} / S_{12}\right)^{2} \geq 1$

$\sigma_{2} / Y_{C}\left[\left(Y_{C} / 2 S_{23}\right)^{2}-1\right]+\left(\sigma_{2} / 2 S_{23}\right)^{2}+\left(\tau_{12} / S_{12}\right)^{2} \geq 1$

$\sqrt{\left(\sigma_{2} / Y_{C}\right)^{2}+\frac{\tau_{12}{ }^{2} / 2 G_{12}+\frac{3}{4} \alpha \tau_{12}{ }^{4}}{S_{12 \text { is }}{ }^{2} / 2 G_{12}+\frac{3}{4} \alpha S_{12 \text { is }}{ }^{4}} \geq 1} \quad \begin{array}{ll}\alpha \text { from nonlinear shear } \\ \gamma_{12}=\tau_{12} / G_{12}+\alpha \tau_{12}{ }^{3}\end{array}$

for 2D plane stress

Mode B, $\theta_{f p}=0^{\circ}$,

$\frac{1}{S_{21}}\left(\sqrt{\tau_{21}{ }^{2}+\left(p_{\perp \|}{ }^{(-)} \sigma_{2}\right)^{2}}+p_{\perp \|}{ }^{(-)} \sigma_{2}\right) \geq 1-\left|\frac{\sigma_{1}}{\sigma_{1 D}}\right|$

for $\sigma_{2}<0$ and $0 \leq\left|\sigma_{2} / \tau_{21}\right| \leq R_{\perp \perp}{ }^{A} /\left|\tau_{21 c}\right|$

Mode C: $\theta_{f p} \neq 0^{\circ}\left(\theta_{f p}\right.$ equation in paper)

$\left[\left(\frac{\tau_{21}}{2\left(1+p_{\perp \perp}{ }^{(-)} S_{21}\right)}\right)^{2}+\left(\frac{\sigma_{2}}{Y_{C}}\right)\right] \frac{Y_{C}}{\left(-\sigma_{2}\right)} \geq 1-\left|\frac{\sigma_{1}}{\sigma_{1 D}}\right|$

for $\sigma_{2}<0$ and $0 \leq\left|\tau_{21} / \sigma_{2}\right| \leq\left|\tau_{21 c}\right| / R_{\perp \perp}{ }^{A}$

$\sigma_{1}<Y_{C}: \tau_{23 \text { eff }}^{m} / S_{23}+\tau_{12 \text { eff }}^{m} / S_{12 \text { is }} \geq 1$

$\sigma_{1} \geq Y_{C}: \tau_{23 \text { eff }} / S_{23}+\tau_{12 \text { eff }} / S_{12 \text { is }} \geq 1$

$\tau_{23 \text { eff }}{ }^{m}, \tau_{12 \text { eff }}{ }^{m}$ :stresses in 2D kink frame, at $\varphi$

$p_{\perp \|}^{(-)}=-\left(d \tau_{21} / d \sigma_{2}\right)_{\sigma_{2}=0}$

$R_{\perp \perp}{ }^{A}=Y_{C} /\left\{2\left(1+p_{\perp \perp}{ }^{(-)}\right)\right\}$

$R_{\perp \perp}{ }^{A}=S_{21} / 2 p_{\perp \|}{ }^{(-)} \times$

$\left(\sqrt{1+2 p_{\perp \|}^{(-)} Y_{C} / S_{21}}-1\right)$

$p_{\perp \perp}{ }^{(-)}=p_{\perp \|}{ }^{(-)} R_{\perp \perp}{ }^{A} / S_{21}$

$\tau_{21}=S_{21} \sqrt{1+2 p_{\perp \perp}{ }^{(-)}}$

$f_{w}=1-\sigma_{1} / \sigma_{1 D}$

$\sigma_{1 D}:$ stress value for linear degradation

$\alpha_{0}=53^{\circ}$ or test data

angle $\alpha$ found by checking 0

$<\alpha<\alpha_{0}$

$S_{23}=Y_{C} \cos \alpha_{0} \times$

$\left(\sin \alpha_{0}+\cos \alpha_{0} / \tan 2 \alpha_{0}\right)$

$b_{\perp}{ }^{\tau}=1, b_{\perp \|}{ }^{\tau}=0$

_matrix-comp [24]

$\left(b_{\perp}{ }^{\tau}-1\right) I_{2} / Y_{C}+\left(b_{\perp}{ }^{\tau} I_{4}+b_{\perp \|}{ }^{\tau} I_{3}\right) / Y_{C}{ }^{2} \geq 1$

$I_{2}=\sigma_{2}+\sigma_{3}, I_{3}=\tau_{31}{ }^{2}+\tau_{12}{ }^{2}, I_{4}=\left(\sigma_{2}-\sigma_{3}\right)^{2}+4 \tau_{23}{ }^{2}$

2005_LaRC04

_matrix-comp [22]

$\sigma_{1} \geq-Y_{C}:\left(\frac{\tau_{23}{ }^{\alpha}}{S_{23}-\eta_{23} \sigma_{n}}\right)^{2}+\left(\frac{\tau_{12}{ }^{\alpha}}{S_{12 \text { is }}-\eta_{12} \sigma_{n}}\right)^{2} \geq 1$

$\sigma_{1}<-Y_{C}:\left(\frac{\tau_{23}{ }^{m}}{S_{23}-\eta_{23} \sigma_{n}{ }^{m}}\right)^{2}+\left(\frac{\tau_{12}{ }^{m}}{S_{12}-\eta_{12} \sigma_{n}{ }^{m}}\right)^{2} \geq 1$

$\sigma_{n}, \tau_{23}{ }^{\alpha}, \tau_{12}{ }^{\alpha}:$ stresses in fracture plane, at $\alpha$

$\sigma_{n}{ }^{m}, \tau_{23}{ }^{m}, \tau_{12}{ }^{m}$ : stresses in 3D kink frame, at $\phi, \varphi$

2007_Maimí-et-al _matrix-comp [44]

$$
\begin{aligned}
& \sqrt{\left(\tau_{23 \text { eff }} / S_{23}\right)^{2}+\left(\tau_{12 \text { eff }} / S_{12}\right)^{2}} \geq 1 \\
& \alpha_{0}=53^{\circ}, \theta=\arctan \left(-\sigma_{12} / \sigma_{22} \sin \alpha_{0}\right) \\
& \tau_{23 \text { eff }}=\left\langle-\sigma_{22} \cos \alpha_{0}\left(\sin \alpha_{0}-\eta_{23} \cos \alpha_{0} \cos \theta\right)\right\rangle \\
& \tau_{12 \text { eff }}=\left\langle\cos \alpha_{0}\left(\left|\tau_{12}\right|+\eta_{12} \sigma_{22} \cos \alpha_{0} \sin \theta\right)\right\rangle
\end{aligned}
$$

or equations in paper

$\alpha_{0}=53^{\circ}$ or test data

angle $\alpha$ found by checking 0

$<\alpha<\alpha_{0}$

$S_{23}=Y_{C} \cos \alpha_{0} \times$

$\left(\sin \alpha_{0}+\cos \alpha_{0} / \tan 2 \alpha_{0}\right)$

$\eta_{23}=-1 / \tan 2 \alpha_{0}$

$\eta_{12}=\eta_{23} S_{12} / S_{23}$

$\eta_{23}=-1 / \tan 2 \alpha_{0}$,

$\eta_{12}=-\frac{S_{12} \cos 2 \alpha_{0}}{Y_{C} \cos ^{2} 2 \alpha_{0}}$

$S_{23}=Y_{C} \cos \alpha_{0} \times$

$\left(\sin \alpha_{0}+\cos \alpha_{0} / \tan 2 \alpha_{0}\right)$ 
Table 6: Failure criteria for matrix failure in tension and compression

\begin{tabular}{|c|c|c|}
\hline Criterion & Equation & Additional terms \\
\hline $\begin{array}{l}\text { 1982_Lee } \\
\text { _matrix-gen [45] }\end{array}$ & 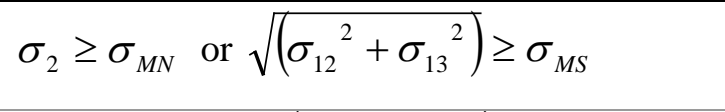 & $\begin{array}{l}\sigma_{M N}, \sigma_{M S}: \text { matrix } \\
\text { normal, shear strengths }\end{array}$ \\
\hline $\begin{array}{l}\text { 1997_Christensen } \\
\text { _matrix-gen [46] }\end{array}$ & $\begin{array}{l}\alpha_{1} k_{1}\left(\sigma_{2}+\sigma_{3}\right)+\left(\sigma_{12}^{2}+\sigma_{31}^{2}\right) \\
+\left(1+2 \alpha_{1}\right)\left[\frac{1}{4}\left(\sigma_{2}-\sigma_{3}\right)^{2}+\sigma_{23}^{2}\right] \leq k_{1}^{2} \\
k_{1}=S_{12}=\frac{1}{2}\left|Y_{C}\right|, \alpha_{1}=\frac{1}{2}\left(\left|Y_{C}\right| / Y_{T}-1\right)\end{array}$ & $\begin{array}{l}\text { restrictions: } \\
k_{1}<<k_{2} \text { (in Table 3) } \\
\left|\frac{1}{2}\left(\sigma_{22}+\sigma_{33}\right)\right|=\operatorname{order}\left(k_{1}\right)\end{array}$ \\
\hline $\begin{array}{l}\text { 2001_Gosse } \\
\text { matrix-gen [50] }\end{array}$ & $\begin{array}{l}J_{1}=\varepsilon_{1}+\varepsilon_{2}+\varepsilon_{3} \text { or } \\
\varepsilon_{\text {eqv }}=\sqrt{\frac{\left(\varepsilon_{1}-\varepsilon_{2}\right)^{2}+\left(\varepsilon_{1}-\varepsilon_{3}\right)^{2}+\left(\varepsilon_{2}-\varepsilon_{3}\right)^{2}}{2}} \\
\text { failure when } J_{1} \geq J_{1 \text { crit }} \text { or } \varepsilon_{\text {eqv }} \geq \varepsilon_{\text {eqv }} \text { crit }\end{array}$ & $\begin{array}{l}\varepsilon_{1}, \varepsilon_{2}, \varepsilon_{3}: \text { principal } \\
\text { strains } \\
J_{1 \text { crit }}, \varepsilon_{\text {eqv }}: \text { frit } \\
\text { experiment }\end{array}$ \\
\hline $\begin{array}{l}\text { 2003_Huang-et-al } \\
\text { matrix-gen [47] }\end{array}$ & $\begin{array}{l}\text { use dissipated energy density } \phi(\varepsilon) \text { : } \\
\text { matrix failure for } 0 \leq \phi(\varepsilon) \leq D_{t}\end{array}$ & $\begin{array}{l}D_{t}: \text { dissipated energy } \\
\text { density threshold }\end{array}$ \\
\hline
\end{tabular}


Table 7: Failure criteria for fibre-matrix shear failure

\begin{tabular}{|c|c|c|}
\hline Criterion & Equation & Additional terms \\
\hline Max-stress_shear & $\tau_{12} \geq S_{12}$ & \\
\hline Max-strain_shear & $\gamma_{12} \geq \gamma_{12}^{u}$ & $\gamma_{12}{ }^{u}:$ ultimate shear strain \\
\hline $\begin{array}{l}\text { 1980_Hashin } \\
\text { _shear [19] }\end{array}$ & $\left(\sigma_{1} / X_{T}\right)^{2}+\left(\tau_{12} / S_{12}\right)^{2} \geq 1$ & \\
\hline $\begin{array}{l}\text { 1991_Chang-Lessard } \\
\text { _shear [25] }\end{array}$ & $\sqrt{\left(\frac{\sigma_{1}}{X_{C}}\right)^{2}+\frac{\tau_{12}{ }^{2} / 2 G_{12}+\frac{3}{4} \alpha \tau_{12}{ }^{4}}{S_{12 \text { is }}{ }^{2} / 2 G_{12}+\frac{3}{4} \alpha S_{12 i s}{ }^{4}}} \geq 1$ & $\begin{array}{l}\alpha \text { from nonlinear shear } \\
\gamma_{12}=\tau_{12} / G_{12}+\alpha \tau_{12}{ }^{3}\end{array}$ \\
\hline $\begin{array}{l}\text { 1992_Ladeveze } \\
\text { _shear [48] }\end{array}$ & $\begin{array}{l}\text { use } d_{12}, \bar{\Psi}_{12} \text { and } \bar{\Psi}_{2} \text { to indicate damage: } \\
\text { total failure for } d_{12} \geq 1 \bar{\Psi}_{2} \geq \Psi_{2 \max } \\
d_{1,12}=\left\langle\bar{\Psi}_{1,12}-\Psi_{1,12 \text { init }}\right\rangle_{+} / \Psi_{1,12 \text { crit }}, \\
\bar{\Psi}_{12}(t)=\sqrt{\tau_{12}^{2} /\left(2 G_{12}\left(1-d_{12}\right)^{2}\right)+b \bar{\Psi}_{2}(t)} \\
\bar{\Psi}_{2}(t)=\sqrt{\frac{1}{2} \frac{\left\langle\sigma_{2}\right\rangle_{+}^{2}}{E_{2}\left(1-d_{2}\right)^{2}}}, \bar{\Psi}_{12}=\max \bar{\Psi}_{12}(t)\end{array}$ & $\begin{array}{l}\langle a\rangle_{+}=a \text { if } a \geq 0 \text {, else } 0 \\
\text { material parameters: } \\
\Psi_{2 \text { init }}, \text { crit }, \text { max }, b \text { : tension } \\
\text { test on }[ \pm 67.5]_{2 S} \text { coupon } \\
\Psi_{12 \text { init }}, \Psi_{12 \text { crit }}: \text { cyclic tension } \\
\text { on }[ \pm 45]_{2 S} \text { coupon } \\
\text { Also uses plasticity law }\end{array}$ \\
\hline $\begin{array}{l}\text { 1995_Shahid-Chang } \\
\text { _shear [49] }\end{array}$ & $\left(\bar{\sigma}_{1} / X_{T}\right)^{2}+\left(\bar{\tau}_{12} / S_{12}(\phi)\right)^{2} \geq 1$ & $\begin{array}{l}\bar{\sigma}: \text { effective ply stresses } \\
\phi: \text { matrix crack density }\end{array}$ \\
\hline $\begin{array}{l}\text { 2004_Cuntze } \\
\text { _shear [24] }\end{array}$ & $\begin{array}{l}{\left[I_{3}^{3 / 2}+b_{\perp \|}\left(I_{2} I_{3}-I_{5}\right)\right]^{1 / 3} / S_{12} \geq 1} \\
I_{2}=\sigma_{2}+\sigma_{3}, I_{3}=\tau_{31}{ }^{2}+\tau_{12}{ }^{2} \\
I_{5}=\left(\sigma_{2}-\sigma_{3}\right)\left(\tau_{31}{ }^{2}+\tau_{12}{ }^{2}\right)-4 \tau_{23} \tau_{31} \tau_{12}\end{array}$ & $\begin{array}{l}b_{\perp \|}=0.1 \\
\text { or equation in paper }\end{array}$ \\
\hline
\end{tabular}


Table 8: Failure criteria for ply failure

\begin{tabular}{|c|c|c|}
\hline Criterion & Equation & Additional terms \\
\hline $\begin{array}{l}\text { 1974_Sandhu } \\
\text { _ply-gen [51] }\end{array}$ & $\left(\frac{\int_{\varepsilon_{1}} \sigma_{1} d \varepsilon_{1}}{\int_{\varepsilon_{1}{ }^{u}} \sigma_{1} d \varepsilon_{1}}\right)^{m}+\left(\frac{\int_{\varepsilon_{2}} \sigma_{2} d \varepsilon_{2}}{\int_{\varepsilon_{2}{ }^{u}} \sigma_{2} d \varepsilon_{2}}\right)^{m}+\left(\frac{\int_{\varepsilon_{1}} \tau_{12} d \gamma_{12}}{\int_{\gamma_{12}{ }^{u}} \tau_{12} d \gamma_{12}}\right)^{m} \geq 1$ & $\begin{array}{l}()^{u}: \text { ultimate strain } \\
m \text { : curve fit parameter } \\
\text { Wolfe and Butalia (1998) use } \\
m_{1}, m_{2}, m_{12} \text { for } m\end{array}$ \\
\hline $\begin{array}{l}\text { 1980_Yamada-Sun } \\
\text { _ply-gen [52] }\end{array}$ & $\begin{array}{l}\left(\sigma_{1} / X\right)^{2}+\left(\tau_{12} / S_{12 \text { is }}\right)^{2} \geq 1 \\
\text { 2-parameter Weibull distribution for strength }\end{array}$ & $\begin{array}{l}\text { X: specified in paper only as } \\
\text { ply strength }\end{array}$ \\
\hline $\begin{array}{l}\text { 1988_Christensen } \\
\text { _ply-gen [53] }\end{array}$ & $\begin{array}{l}\alpha \cdot \varepsilon_{k k}+e_{i j} e_{i j} \leq k^{2}, \text { where } \\
\varepsilon_{k k}: \text { volume change, } e_{i j}: \text { deviatoric strain }\end{array}$ & $\alpha, k$ : curve fit parameters \\
\hline $\begin{array}{l}\text { 1997_Michopoulos_et-al } \\
\text { _ply-gen [2] }\end{array}$ & $\begin{array}{l}\text { use dissipated energy density } \phi \text { as damage metric: } \\
\text { from experiment, measure } D=W-R \\
\Phi=\int_{\partial V} \phi(\varepsilon, m) d V=\int_{\partial V} c_{i}(m) \chi_{i}(\varepsilon) d V \\
e=|D-\Phi| \text {, solve for } c_{i} \text { by minimising } e \\
\phi \text { measures nonlinearity caused by damage } \\
\text { Apply to structures with a dominant flaw, mechanically } \\
\text { loaded with loading vector } L \text { : } \\
\frac{d V_{c}}{d||_{\sim}^{L} \mid}=0, \frac{d^{2}}{d||_{\sim}^{2}} V_{c}=0, \frac{d}{\left.\left.d\right|_{\sim} ^{L}\right|_{0} ^{V_{c}}} \phi d v=0, \int_{0}^{V_{c}} \phi d v \geq d_{c r}\end{array}$ & $\begin{array}{l}D: \text { dissipated energy } \\
W: \text { total energy, } \\
R: \text { recoverable energy } \\
\Phi: \text { dissipated energy } \\
\text { (approximation) } \\
m: \text { material, } V \text { : volume } \\
\chi: \text { strain-based interpolation } \\
\text { functions } \\
c: \text { material coefficients } \\
V_{c}: \text { characteristic volume } \\
d_{c r}: \text { critical dissipated energy }\end{array}$ \\
\hline $\begin{array}{l}\text { 2004_Cuntze } \\
\text { _ply-gen [24] }\end{array}$ & $\sum_{1}^{5}\left(E f f^{\text {mode }}\right)^{\dot{m}}$, Eff mode : failure mode criteria & $\begin{array}{l}\dot{m}: \text { curve-fit parameter, can } \\
\text { take } \dot{m}=3.1\end{array}$ \\
\hline
\end{tabular}


Table 9: Interactive failure criteria for ply failure

Criterion

1965_Tsai-Hill

_ply-inter [54-55]

1967_Hoffman

_ply-inter [56]

1971_Tsai-Wu

_ply-inter [57]

1992_Theocaris

_ply-inter [58]

1994_Yeh-Stratton

_ply-inter [59]

\section{Equation}

$\left(\sigma_{1} / X\right)^{2}+\left(\sigma_{2} / Y\right)^{2}+\left(\tau_{12} / S_{12}\right)^{2}-\left(\sigma_{1} \sigma_{2} / X^{2}\right) \geq 1$

$X$ and $Y$ are either $X_{C}, Y_{C}$ or $X_{T}, Y_{T}$ depending on sign of $\sigma_{1}, \sigma_{2}$

$\left(\frac{1}{X_{T}}-\frac{1}{X_{C}}\right) \sigma_{1}+\left(\frac{1}{Y_{T}}-\frac{1}{Y_{C}}\right) \sigma_{2}+\frac{\sigma_{1}{ }^{2}}{X_{T} X_{C}}+\frac{\sigma_{2}{ }^{2}}{Y_{T} Y_{C}}+\left(\frac{\tau_{12}}{S_{12}}\right)^{2}-\frac{\sigma_{1} \sigma_{2}}{X_{T} X_{C}} \geq 1$

$\left(\frac{1}{X_{T}}-\frac{1}{X_{C}}\right) \sigma_{1}+\left(\frac{1}{Y_{T}}-\frac{1}{Y_{C}}\right) \sigma_{2}+\frac{\sigma_{1}^{2}}{X_{T} X_{C}}+\frac{\sigma_{2}^{2}}{Y_{T} Y_{C}}+\left(\frac{\tau_{12}}{S_{12}}\right)^{2}+2 f_{12} \sigma_{1} \sigma_{2} \geq 1$

$f_{12}=-\frac{1}{2} \sqrt{f_{11} f_{22}}$ or $f_{12}=-\frac{1}{2} \sqrt{1 /\left(X_{T} X_{C} Y_{T} Y_{C}\right)}$

for 2D transverse isotropic material

$\frac{\sigma_{1}^{2}}{X_{T} X_{C}}+\frac{\sigma_{2}^{2}}{Y_{T} Y_{C}}-\frac{\sigma_{1} \sigma_{2}}{X_{T} X_{C}}+\left(\frac{1}{X_{T}}-\frac{1}{X_{C}}\right) \sigma_{1}+\left(\frac{1}{Y_{T}}-\frac{1}{Y_{C}}\right) \sigma_{2} \geq 1$

$\frac{\sigma_{i}}{A_{i}}+\frac{\sigma_{j}}{A_{j}}+B_{i j} \sigma_{i j}+\frac{\tau_{i j}{ }^{2}}{C_{i j}} \geq 1$ in every quadrant of stress space

eg for 1-2 plane: $\frac{\sigma_{1}}{X}+\frac{\sigma_{2}}{Y}+B_{12} \sigma_{12}+\frac{\tau_{12}^{2}}{S_{12}} \geq 1$

for $\sigma_{1}>0, X=X_{T}$ else for $\sigma_{1}<0, X=X_{C}$

for $\sigma_{2}>0, Y=Y_{T}$ else for $\sigma_{2}<0, Y=Y_{C}$

note $B_{12}$ parameters different in each quadrant

1997_Echaabi

_ply-inter [60]
Kriging technique for statistical curve fit to failure data use knowledge of slope of envelope in quadrants

$$
\begin{aligned}
& {\left[\begin{array}{ccc}
K\left(\left|X_{i}-X_{j}\right|\right) & \in_{i j} K^{\prime}\left(\left|X_{i}-X_{k}^{*}\right|\right) & P(X) \\
-\in_{i j} K^{\prime}\left(\left|X_{r}^{*}-X_{j}\right|\right) & -K^{\prime \prime}\left(\left|X_{r}^{*}-X_{k}^{*}\right|\right) & P^{\prime}\left(X^{*}\right) \\
P(X) & P^{\prime}\left(X^{*}\right) & 0
\end{array}\right]\left\{\begin{array}{l}
b_{j} \\
c_{k} \\
a_{l}
\end{array}\right\}=\left\{\begin{array}{c}
u_{i} \\
d_{r} \\
0
\end{array}\right\}}
\end{aligned}
$$

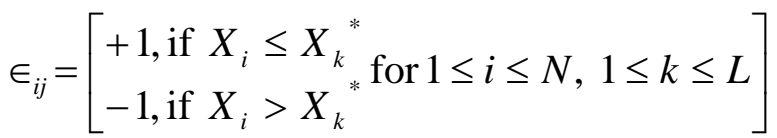

typical covariance types:

constant: $a_{1}$

linear: $a_{1}+a_{2} t$ 
Table 10: Failure criteria for delamination initiation

\section{Criterion}

Max-stress _delam-init

1980_Hashin

_delam-init [19]

1982_Lee

_delam-init [45]

1986_Kim-Soni

_delam-init [61]

\section{Equation}

$\sigma_{3} \geq Z_{T}, \tau_{31} \geq S_{31}, \tau_{23} \geq S_{23}$

$\left(\frac{\sigma_{3}}{Z_{T}}\right)^{2}+\left(\frac{\tau_{23}}{S_{23}}\right)^{2}+\left(\frac{\tau_{31}}{S_{31}}\right)^{2} \geq 1$

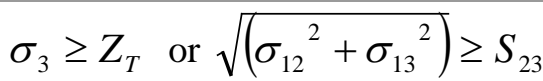

$F_{13} \tau_{13}{ }^{2}+F_{23} \tau_{23}{ }^{2}+F_{33} \sigma_{3}{ }^{2}+F_{3} \sigma_{3} \geq 1$

$F_{i 3}$ and $F_{3}$ are general functions of the interlaminar strengths

$\left(\frac{\sigma_{3}}{Z_{T}}\right)^{2}+\frac{\tau_{23}{ }^{2}+\tau_{31}^{2}}{S_{23}{ }^{2}} \geq 1$

1988_Brewer-Lagace

_delam-init [63]

$\left(\frac{\tau_{23}}{S_{23}}\right)^{2}+\left(\frac{\tau_{31}}{S_{31}}\right)^{2}+\left(\frac{\sigma_{3}{ }^{+}}{Z_{T}}\right)^{2}+\left(\frac{\sigma_{3}{ }^{-}}{Z_{C}}\right)^{2} \geq 1$

1991_Long

_delam-init [64]

$\left(\frac{\sigma_{3}}{Z_{T}}\right)+\left(\frac{\tau_{23}}{S_{23}}\right)^{2} \geq 1$ and $\left(\frac{\sigma_{3}}{Z_{T}}\right)^{2}+\left(\frac{\tau_{23}}{S_{23}}\right)^{2} \geq 1$

1997_Tsai

delam-init [65]

$\frac{\sigma_{1}^{2}-\sigma_{1} \sigma_{3}}{X_{T}^{2}}+\left(\frac{\sigma_{3}}{Z_{T}}\right)^{2}+\left(\frac{\tau_{23}}{S_{23}}\right)^{2} \geq 1$

1997_Tong-Tsai

$\frac{\sigma_{1}^{2}-\sigma_{1} \sigma_{3}}{X_{T}{ }^{2}}+\left(\frac{\sigma_{3}}{Z_{T}}\right)+\left(\frac{\tau_{23}}{S_{23}}\right)^{2} \geq 1$

1997_Degen-Tsai

_delam-init [65]

$\left(\frac{\sigma_{1}}{X_{T}}\right)^{2}+\left(\frac{\sigma_{3}}{Z_{T}}\right)^{2}+\left(\frac{\tau_{23}}{S_{23}}\right)^{2} \geq 1$

1997_Degen-Tong-Tsai

_delam-init [65]

$\left(\frac{\sigma_{1}}{X_{T}}\right)^{2}+\left(\frac{\sigma_{3}}{Z_{T}}\right)+\left(\frac{\tau_{23}}{S_{23}}\right)^{2} \geq 1$

1997_Norris

_delam-init [65]

$\frac{\sigma_{1}^{2}-\sigma_{1} \sigma_{3}}{X_{T} X_{C}}+\left(\frac{\sigma_{3}}{Z_{T}}\right)^{2}+\left(\frac{\tau_{23}}{S_{23}}\right)^{2} \geq 1$

1997_Tong-Norris

_delam-init [65]

$\frac{\sigma_{1}^{2}-\sigma_{1} \sigma_{3}}{X_{T} X_{C}}+\left(\frac{\sigma_{3}}{Z_{T}}\right)+\left(\frac{\tau_{23}}{S_{23}}\right)^{2} \geq 1$

1998_Zhang

delam-init [65]

2001_Wisnom-et-al

_delam-init [29]

2002_Goyal-et-al _delam-init [26]

$$
\sigma_{3} \geq Z_{T} \text { and } \sqrt{\tau_{31}{ }^{2}+\tau_{23}{ }^{2}} \geq S_{23}
$$

effective matrix stress $\sigma_{e}$ found from principal stresses:

$2.6 \sigma_{e}{ }^{2}=\left(\sigma_{1}-\sigma_{2}\right)^{2}+\left(\sigma_{2}-\sigma_{3}\right)^{2}+\left(\sigma_{3}-\sigma_{1}\right)^{2}+0.6 \sigma_{e}\left(\sigma_{1}+\sigma_{2}+\sigma_{3}\right)$

Weibull equivalent stress $\bar{\sigma}$ found summing $\sigma_{e}$ for all elements

Weibull parameter and experimental $\bar{\sigma}$ from testing curved unidirectional beams in bending.

$$
\left(\frac{\tau_{23}}{S_{23}}\right)^{\gamma}+\left(\frac{\tau_{31}}{S_{31}}\right)^{\gamma}+\left(\frac{\sigma_{3}^{+}}{Z_{T}}\right)^{2} \geq 1, \quad \gamma \text { : curve fit parameter }
$$


Table 11: Failure criteria for growth of an existing delamination

\begin{tabular}{|c|c|c|}
\hline Criterion & Equation & Additional terms \\
\hline Single mode & $G_{I} \geq G_{I_{C}}, G_{I I} \geq G_{I I c}, G_{I I I} \geq G_{I I I_{C}}$ & \\
\hline $\begin{array}{l}\text { 1981_Hahn } \\
\text { delam-growth [67] }\end{array}$ & $G_{T} \geq G_{I I c}-\left(G_{I I c}-G_{I c}\right) \sqrt{G_{I} / G_{I c}}$ & \\
\hline $\begin{array}{l}\text { 1983_Hahn-Johnnesson } \\
\text { _delam-growth [68] }\end{array}$ & $G_{T} \geq\left(G_{I_{C}}-\chi\right)+\chi \sqrt{1+\frac{G_{I I}}{G_{I}} \sqrt{\frac{E_{11}}{E_{22}}}}$ & $\chi:$ curve fit \\
\hline $\begin{array}{l}\text { 1984_Power-law } \\
\text { _delam-growth [69] }\end{array}$ & $\left(\frac{G_{I}}{G_{I c}}\right)^{m}+\left(\frac{G_{I I}}{G_{I I c}}\right)^{n}+\left(\frac{G_{I I}}{G_{I I c}}\right)^{p} \geq 1$ & $\begin{array}{l}m, n, p: \text { curve-fit } \\
\text { linear: } m=n=p=1 \\
\text { quadratic: } m=n=p=2\end{array}$ \\
\hline $\begin{array}{l}\text { 1985_Donaldson } \\
\text { _delam-growth [70] }\end{array}$ & $\begin{array}{l}G_{T} \geq\left(G_{I c}-G_{I I C}\right)+e^{\gamma(1-N)} \\
N=\sqrt{1+\left(G_{I I} / G_{I}\right)\left(\sqrt{E_{11} / E_{22}}\right)}\end{array}$ & $\gamma:$ curve fit \\
\hline $\begin{array}{l}\text { 1987_Hashemi-Kinloch } \\
\text { _delam-growth [71] }\end{array}$ & $\begin{array}{l}\text { mode I: } G_{I I} \geq \frac{1}{3} G_{I I c} \sqrt{\frac{E_{11}}{E_{22}}}\left(\frac{G_{I_{C}}}{G_{I}}-\frac{G_{I}}{G_{I c}}\right) \\
\text { mode II: } G_{I} \geq 3 G_{I c} \sqrt{\frac{E_{22}}{E_{11}}}\left(\frac{G_{I_{c}}}{G_{I I}}\left(\frac{G_{I I_{c}}}{G_{I_{c}}}\right)^{2}-\frac{G_{I I}}{G_{I c}}\right)\end{array}$ & \\
\hline $\begin{array}{l}\text { 1987_White } \\
\text { _delam-growth [72] }\end{array}$ & $G_{T} \geq\left(G_{I I_{C}}-G_{I_{C}}\right) e^{\eta \sqrt{\frac{1}{\left(G_{I I} / G_{I}\right)}}}$ & $\eta$ : curve fit \\
\hline $\begin{array}{l}\text { 1990_Hashemi-Kinloch } \\
\text { _delam-growth [73] }\end{array}$ & $\frac{G_{I}}{G_{I c}}+(\kappa-1) \frac{G_{I}}{G_{I c}} \frac{G_{I I}}{G_{I I c}}+\frac{G_{I I}}{G_{I I c}} \geq 1$ & $\kappa:$ curve fit \\
\hline $\begin{array}{l}\text { 1991_Yan-et-al } \\
\text { _delam-growth [74] }\end{array}$ & $G_{T} \geq G_{I c}+\rho \frac{G_{I I}}{G_{I}}+\tau\left(\frac{G_{I I}}{G_{I}}\right)^{2}$ & $\rho, \tau$ : curve fit \\
\hline $\begin{array}{l}\text { 1991_Hashemi-Williams } \\
\text { _delam-growth [75] }\end{array}$ & $\frac{G_{I}}{G_{I c}}+\left(\frac{\kappa-1+\varphi}{1+G_{I I} / G_{I}}\right) \frac{G_{I}}{G_{I c}} \frac{G_{I I}}{G_{I I c}}+\frac{G_{I I}}{G_{I I c}} \geq 1$ & $\kappa, \varphi:$ curve fit \\
\hline $\begin{array}{l}\text { 1993_Reeder } \\
\text { _delam-growth [76] }\end{array}$ & $\begin{array}{l}\text { for } \frac{G_{I I}}{G_{I}}<\frac{\frac{1}{\zeta} G_{I c}+G_{I I c}}{G_{I c}+\xi G_{I I c}}, \frac{G_{I}-\xi G_{I I}}{G_{I c}} \geq 1 \\
\text { for } \frac{G_{I I}}{G_{I}}<\frac{\frac{1}{\zeta} G_{I c}+G_{I I c}}{G_{I c}+\xi G_{I I c}}, \frac{\zeta G_{I I}-G_{I}}{\zeta G_{I I c}} \geq 1\end{array}$ & $\xi, \zeta$ : linear curve fit \\
\hline $\begin{array}{l}\text { 1996_B-K } \\
\text { _delam-growth [77] }\end{array}$ & $G_{T} \geq G_{I C}+\left(G_{I I C}-G_{I C}\right)\left[G_{I I} /\left(G_{I}+G_{I I}\right)\right]^{\eta}$ & $\eta$ : curve fit \\
\hline $\begin{array}{l}\text { 2007_Davidson-Zhao } \\
\text { _delam-growth [78] }\end{array}$ & $\begin{array}{l}\text { for } 0 \leq \frac{G_{I I}}{G} \geq Z: G_{T} \geq \frac{G_{I c}}{1-(1+\xi)\left(G_{I I} / G_{T}\right)}, \\
\text { for } Z \leq \frac{G_{I I}}{G} \geq 1.0: G_{T} \geq \frac{\zeta G_{I I c}}{(1+\zeta)\left(G_{I I} / G_{T}\right)-1}\end{array}$ & $\begin{array}{l}\xi, \zeta: \text { linear curve fit from } \\
G_{c} \text { data at DCB }\left(G_{I c}\right) \text {, } \\
\text { ENF }\left(G_{I I c}\right) \text { and one other } \\
\text { mixed-mode ratio, } Z \text {. SLB } \\
\text { test used, with } Z=0.4\end{array}$ \\
\hline
\end{tabular}


Table 12: Interface element summary

\begin{tabular}{|c|c|c|c|c|c|}
\hline Reference & Type & Mixed-mode formulation & $\begin{array}{c}\text { Additional } \\
\text { constants }\end{array}$ & $\begin{array}{c}\text { Additional } \\
\text { tests }\end{array}$ & Structures analysed \\
\hline $\begin{array}{l}\text { Cui and } \\
\text { Wisnom [79] }\end{array}$ & $\begin{array}{l}2 \text { springs per node } \\
\text { for } 2 \mathrm{D} \text { models }\end{array}$ & Mixed-mode loading not incorporated & - & - & $\begin{array}{l}\text { 2D beams in tension } \\
\text { and 3-point bending }\end{array}$ \\
\hline $\begin{array}{l}\text { Hachenberg } \\
\text { and Kossira } \\
\text { [80] }\end{array}$ & $\begin{array}{l}12 \text { node interface, for } \\
\text { use with } \\
8 \text { node shell }\end{array}$ & Delamination growth not incorporated & $\begin{array}{l}\text { critical bending } \\
\text { strain } \beta_{\mathrm{c}}\end{array}$ & $\begin{array}{l}\text { T-peel, ILS } \\
\text { and peel test }\end{array}$ & $\begin{array}{l}\text { 2D specimens, 3D } \\
\text { stiffened panels }\end{array}$ \\
\hline $\begin{array}{l}\text { Schellekens } \\
\text { and de Borst } \\
\text { [81] }\end{array}$ & $\begin{array}{l}8 \text { node line interface } \\
\text { for } \\
12 \text { node shells }\end{array}$ & Mixed-mode loading not incorporated & - & - & $\begin{array}{l}\text { 2D mode I test } \\
\text { specimen }\end{array}$ \\
\hline $\begin{array}{l}\text { Reedy, Mello } \\
\text { and Guess } \\
{[82]}\end{array}$ & $\begin{array}{l}8 \text { node hex interface } \\
\text { for } 4 \text { node shells }\end{array}$ & Mixed-mode loading not incorporated & - & - & $\begin{array}{l}\text { 2D mode I and II } \\
\text { specimens }\end{array}$ \\
\hline Mi et al. [83] & $\begin{array}{l}6 \text { node line interface } \\
\text { for } 8 \text { node shells }\end{array}$ & $\begin{array}{l}\text { Modes I and II, use interaction } \\
\text { exponent } \alpha \text { for delamination growth }\end{array}$ & $\begin{array}{l}\text { Mixed-mode: } \\
\qquad \alpha\end{array}$ & - & $\begin{array}{l}\text { 2D mode I, II, mixed- } \\
\text { mode and overlap } \\
\text { specimens }\end{array}$ \\
\hline $\begin{array}{l}\text { Petrossian and } \\
\text { Wisnom [84] }\end{array}$ & $\begin{array}{l}2 \text { node spring for use } \\
\text { with } 2 \mathrm{D} \text { shells }\end{array}$ & $\begin{array}{l}\text { Linear interaction for delamination } \\
\text { growth using modes I and II }\end{array}$ & - & $\begin{array}{l}\text { FE tests } \\
\text { required }\end{array}$ & $\begin{array}{l}\text { 2D beams and curved } \\
\text { specimens }\end{array}$ \\
\hline $\begin{array}{l}\text { Wisheart and } \\
\text { Richardson } \\
\text { [85] }\end{array}$ & $\begin{array}{l}6 \text { node } 2 \mathrm{D} \text { line and } 16 \\
\text { node } 3 \mathrm{D} \text { interface }\end{array}$ & $\begin{array}{l}\text { Linear interaction for delamination } \\
\text { growth using modes I and II }\end{array}$ & - & - & $\begin{array}{l}\text { 2D and 3D mode I, II, } \\
\text { mixed-mode } \\
\text { specimens }\end{array}$ \\
\hline $\begin{array}{l}\text { de Moura et } \\
\text { al. [86] }\end{array}$ & $\begin{array}{l}18 \text { node } 3 D \text { hex for } \\
\text { use with } \\
27 \text { node hex }\end{array}$ & $\begin{array}{l}\text { Single mode softening, with } \\
\text { displacements in modes I, II, III to } \\
\text { define mixed-mode state }\end{array}$ & - & - & 3D CAI plate test \\
\hline $\begin{array}{l}\text { Jansson and } \\
\text { Larsson [87] }\end{array}$ & $\begin{array}{l}\text { 2D plane strain } \\
\text { damage formulation, }\end{array}$ & $\begin{array}{l}\text { Linear addition of mode I and II } \\
\text { SERR; then equate to experimental } \\
\text { fracture toughness at given mixed- } \\
\text { mode ratio }\end{array}$ & $\begin{array}{l}\mathrm{G} \text { as } \mathrm{fn} \text { of } \\
\text { mode ratio } \\
\mathrm{G}(\beta)\end{array}$ & $\begin{array}{l}\text { Input data for } \\
G(\beta) \text { equation }\end{array}$ & $\begin{array}{l}\text { 2D mode I, II and } \\
\text { MMB specimens }\end{array}$ \\
\hline $\begin{array}{l}\text { Qiu, Crisfield } \\
\text { and Alfano } \\
\text { [88] }\end{array}$ & $\begin{array}{l}4 \text { node line interface } \\
\text { for use with 2D shells }\end{array}$ & $\begin{array}{l}\text { Interaction formulation of } \\
\text { Mi et al. [83] }\end{array}$ & $\begin{array}{l}\text { Mixed-mode: } \\
\alpha \alpha\end{array}$ & - & 2D mode I specimen \\
\hline $\begin{array}{l}\text { Borg, Nilsson } \\
\text { and } \\
\text { Simonsson } \\
\text { [89] }\end{array}$ & $\begin{array}{l}3 \text { springs per node in } \\
3 \mathrm{D} \text { damage surface } \\
\text { formulation }\end{array}$ & $\begin{array}{l}\text { Mixed-mode power law relationships } f \\
\text { and } g \text { for stresses and strain energy } \\
\text { release rates into damage surface }\end{array}$ & $\begin{array}{l}8 \text { constants } \\
\text { Load:, } \alpha_{0}, \alpha_{i} \\
\text { Energy: } \beta_{0}, \beta_{\mathrm{i}}\end{array}$ & $\begin{array}{c}\alpha_{\mathrm{i}} \text { and } \beta_{\mathrm{i}} \\
\text { chosen based } \\
\text { on tests }\end{array}$ & $\begin{array}{l}\text { 3D DCB, ENF and } \\
\text { MMB specimens }\end{array}$ \\
\hline $\begin{array}{l}\text { Camanho and } \\
\text { Dávila [30] }\end{array}$ & $\begin{array}{l}8 \text { or } 18 \text { node } 3 D \\
\text { interface for } 8 \text { or } 21 \\
\text { node bricks }\end{array}$ & $\begin{array}{l}\text { Quadratic interaction for delamination } \\
\text { initiation; } \\
\text { Benzaggagh and Kenane [77] fracture } \\
\text { toughness criteria with } \\
\mathrm{G}_{\text {shear }}=\mathrm{G}_{\mathrm{II}}+\mathrm{G}_{\mathrm{III}} \text { for growth }\end{array}$ & $\begin{array}{l}\text { Mixed-mode: } \eta \\
\text { for B-K } \\
\text { criterion }\end{array}$ & $\begin{array}{l}\text { Series of } \\
\text { mixed-mode } \\
\text { tests for } \eta\end{array}$ & $\begin{array}{l}\text { 2D DCB, 3D ENF and } \\
\text { MMB specimens }\end{array}$ \\
\hline Zou et al. [90] & $\begin{array}{l}16 \text { node non-cohesive } \\
\text { interface for } 8 \text { node } \\
\text { degenerated shell }\end{array}$ & $\begin{array}{l}\text { Interaction formula (Eqn 1) with } \\
\text { exponents } \alpha, \beta \text { and } \gamma \text { for growth in } \\
\text { modes I, II and III }\end{array}$ & $\begin{array}{l}\text { Mixed-mode: } \\
\quad \alpha, \beta, \gamma\end{array}$ & - & $\begin{array}{l}\text { 3D DCB and impact } \\
\text { specimens }\end{array}$ \\
\hline $\begin{array}{l}\text { Zou, Reid and } \\
\text { Li [91] }\end{array}$ & $\begin{array}{l}2 \text { interfaces, for } \\
\text { 2D/3D solids and } \\
\text { laminated shells }\end{array}$ & $\begin{array}{l}\text { Damage surface formulation of Borg, } \\
\text { Nilsson and Simonsson [89], with } g \\
\text { incorporated into another function } \psi \text { to } \\
\text { control damage surface shrinkage rate }\end{array}$ & \multicolumn{2}{|c|}{$\begin{array}{l}\text { As for Borg, Nilsson and } \\
\text { Simonsson [89] }\end{array}$} & $\begin{array}{l}\text { 2D DCB and mixed- } \\
\text { mode overlap } \\
\text { specimen }\end{array}$ \\
\hline $\begin{array}{l}\text { Goyal et al. } \\
\text { [26] }\end{array}$ & $\begin{array}{l}8 \text { node interface for } \\
\text { 2D shells, } \\
\text { with PFA applied }\end{array}$ & $\begin{array}{l}\text { Parameter } \mu \text { combining displacements } \\
\text { in modes I, II,III; use } \mu \text { in exponential } \\
\text { softening relationship }\end{array}$ & $\begin{array}{l}\text { Material: } \\
\beta, \kappa, \text { e, } \\
\text { mixed-mode: } \alpha\end{array}$ & - & $\begin{array}{l}\text { 3D shear and } \\
\text { compression panels } \\
\text { with cutouts }\end{array}$ \\
\hline
\end{tabular}

